\title{
The Most Primitive Extant Ancestor of Organisms and Discovery of Definitive Evolutionary Equations Based on Complete Genome Structures
}

\author{
Kenji Sorimachi ${ }^{1,2}$ \\ ${ }^{1}$ Educational Support Center, Dokkyo Medical University, Mibu, Tochigi, Japan; ${ }^{2}$ Bioresearch Laboratory, Gunma \\ Agriculture and Forest Development, Co. Ltd., Takasaki, Gunma, Japan
}

Correspondence to: Kenji Sorimachi, kenjis@dokkyomed.ac.jp

Keywords: Primitive, Organisms, Evolutionary Equations

Received: August 7, $2018 \quad$ Accepted: September 27, 2018

Published: September 30, 2018

Copyright $\odot 2018$ by author and Scientific Research Publishing Inc.

This work is licensed under the Creative Commons Attribution International License (CC BY 4.0).

http://creativecommons.org/licenses/by/4.0/

\section{(c) (i) Open Access}

\section{ABSTRACT}

Evolutionary divergence has been characterized based on morphological and molecular features using rationale based on Darwin's theory of natural selection. However, universal rules that govern genome evolution have not been identified. Here, a simple, innovative approach has been developed to evaluate biological evolution initiating the origin of life: whole genomes were divided into several fragments, and then differences in normalized nucleotide content between nucleotide pairs were compared. Intramolecular nucleotide differences in complete mitochondrial genomes reflect evolutionary divergence. The values of $(G-C),(G-T),(G-A),(C-T),(C-A)$ and $(T-A)$ reflect biological evolution, and these values except for $(G-C)$ and $(T-A)$ change inversely to positive from negative along biological evolution of bacterial genomes. More highly evolved organisms, such as primates and birds, seem to have greater levels of $(\mathrm{C}-\mathrm{T})$ in mitochondria. Based on nucleotide content structures, Monosiga brevicollis mitochondria may be the most primitive extant ancestor of the species examined here. The two normalized nucleotide contents are universally expressed by a linear regression line, $(\mathrm{X}-\mathrm{Y}) /(\mathrm{X}+\mathrm{Y})=\mathrm{a}(\mathrm{X}-\mathrm{Y})+\mathrm{b}$, where $\mathrm{X}$ and $\mathrm{Y}$ are nucleotide contents and (a) and (b) are constants. The value of $(G+C),(G+A),(G+T),(C$ $+\mathrm{A}),(\mathrm{C}+\mathrm{T})$ and $(\mathrm{A}+\mathrm{T})$ was $\sim 0.5$. Plotting $(\mathrm{X}-\mathrm{Y}) /(\mathrm{X}+\mathrm{Y})$ against $\mathrm{X} / \mathrm{Y}$ showed a logarithmic function $(\mathrm{X}-\mathrm{Y}) /(\mathrm{X}+\mathrm{Y})=\mathrm{a} \ln \mathrm{X} / \mathrm{Y}+\mathrm{b}$, where $(\mathrm{a})$ and $(\mathrm{b})$ are constant. Nucleotide content changes are expressed by a definitive equation, $(\mathrm{X}-\mathrm{Y}) \approx 0.25 \ln (\mathrm{X} / \mathrm{Y})$.

\section{INTRODUCTION}

Primitive organisms might appear after long periods of chemical evolution, during which various or-

*This study has been initially posted on BioRxiv: http://biorxiv.org/cgi/content/short/371575v1. 
ganic compounds were accumulated. Recently, it was reported that vesicles consisting of lipids and polynucleotides spontaneously replicated under experimental conditions [1]. These pseudo-organisms were the first living things to appear on Earth; however, we cannot trace their origins because the original assembly of chemical compounds was not stable. Only those primitive organisms that established a method of self-replication could survive and continue to evolve. Therefore, it is difficult to identify the true primitive ancestors of life on Earth, as their very make-up would probably be unstable in the current environmental conditions. Although fossilized traces of very early organisms have been found in sedimentary rocks dating from 3.1 - 3.7 billion years ago [2-5], they do not appear to be the origin of life. It is likely that only primitive organisms that had cell walls could leave a fossil record, which may rule out finding any traces of simpler organisms.

Several key eukaryotic organelles originated from symbioses between separate single-celled organisms $[6,7]$. For example, mitochondria developed from the proteobacterium Rickettsia or its relatives $[8,9]$. The Reclinomonas americana (Protist) mitochondrion $(\sim 70 \mathrm{~kb})$, consisting of 97 genes, is thought to be an ancestral mitochondrial DNA (mtDNA), while vertebrate mtDNA $(\sim 16 \mathrm{~kb})$, consisting of 37 genes, seems to be constructed with only essential genes for respiration reactions. Based on 13 respiratory genes, the amino acid composition and gene patterns within complete mitochondrial genomes are almost identical among all animal species, except Amoebazoa [10]. Irreversible evolutionary divergence accompanied by increasing $\mathrm{G}$ and $\mathrm{C}$ content means that the $\mathrm{G}$ and $\mathrm{C}$ content of descendants should be identical to or higher than that of the ancestor. However, it was shown that the $\mathrm{G}$ and $\mathrm{C}$ values for $R$. americana (G: 0.148, C: 0.114) mtDNA were higher than those of Monosiga brevicollis (G: 0.081, C: 0.059), which were the lowest among the samples examined [11]. In addition, nucleotide regression lines for the two species differed from each other $[11,12]$. Thus, we concluded that mitochondria might derive directly from primitive organisms [13]. Our present results based on genome evolutionary rules deny that the Reclinomonas americana mitochondrion is thought to be an ancestral mitochondrial DNA $[8,9]$. However, there is no scientific evidence that mitochondria are the most primitive extant ancestor of all life. Based on Charles Darwin's theory of natural selection, all organisms have a single origin and common ancestor, therefore, we predict that the amino acid compositions of their complete genomes should naturally reflect their evolution from bacteria to Homo sapiens $[14,15]$.

The two nucleotide relationships were expressed by linear regression lines, which crossed at a single point $[11,12]$. Thus, we concluded that the origin of life was single and pluripotent. Assuming this conclusion, at the crossing point representing the origin of life, $(\mathrm{G} \approx \mathrm{C})$ and $(\mathrm{T} \approx \mathrm{A})$ to satisfy Chargaff s parity rules $[16,17]:(G-C) \approx 0$ and $(T-A) \approx 0$. The two regression lines representing high and low $\mathrm{C} / \mathrm{G}$ animal mitochondria must satisfy $(\mathrm{G} \approx \mathrm{C})$ and $(\mathrm{T} \approx \mathrm{A})$ at the crossing point for the line based on Chargaff's parity rule. Therefore, differences in $(\mathrm{G}-\mathrm{C})$ and $(\mathrm{T}-\mathrm{A})$ reflect mitochondrial evolution. In addition, to satisfy Chargaff's second parity rule [17], the nucleotide content of the first half of the DNA strand should be equal to that of the second half [18], providing a symmetry between the 5' and 3' ends. As animal mitochondrial genomes deviate from Chargaff s second parity rule [17], the divergence in animal mitochondria increases the unsymmetrical nucleotide content. To detect intragenomic alterations based on increases in the unsymmetrical nucleotide content, a method that investigates nucleotide content differences, i.e. $(\mathrm{G}-\mathrm{C}),(\mathrm{G}-\mathrm{A}),(\mathrm{G}-\mathrm{T}),(\mathrm{C}-\mathrm{A}),(\mathrm{C}-\mathrm{T})$ and $(\mathrm{A}-\mathrm{T})$ in the sequentially divided genomes, was developed in the present study. These exciting results could not have been obtained from sequence analyses.

\section{MATERIALS AND METHODS}

All genome sequences were obtained from the National Center for Biotechnology Information GenBank database (http://www.genome.jp/ja). The nucleotide contents of all genomes, which are listed in Extended Data Figs, were normalized $(\mathrm{G}+\mathrm{C}+\mathrm{A}+\mathrm{T}=1)$ because normalized values are independent of species and genome sizes $[19,20]$. A whole genome was divided into several fragments to evaluate intra-genome alterations due to evolution, and the differences between the two nucleotide contents of six 
pairs $((G-C),(G-T),(G-A),(C-T),(C-A),(T-A))$ were calculated for all fragments. In addition, mitochondria were divided into three equal-size fragments. To easily understand evolution at a glance, these six nucleotide differences were graphically expressed with a single pattern. This appears to be a novel approach. Calculations were carried out with a personal computer, TOSHIBA dynabook T552 (Tokyo, Japan), Windows 10 installed.

\section{RESULTS AND DISCUSSION}

\subsection{Primitive Ancestor}

Chargaff's parity rules, where $(\mathrm{G}=\mathrm{C})$ and $(\mathrm{T}=\mathrm{A})$, were the original rules for inter- [16] and intra[17] molecular relationships of DNA, and are applicable to chromosomal DNA [21-23]. The normalized nucleotide contents $(\mathrm{C}, \mathrm{T}$ and $\mathrm{A})$, predicted from complete genomes, are expressed by the content of the fourth nucleotide $(\mathrm{G})$ using linear regression lines in chromosomal [21], non-animal mitochondrial and chloroplast DNA $[22,23]$. Classifying animal mitochondria into high and low $\mathrm{C} / \mathrm{G}$ groups, the content of the first three nucleotides could be similarly expressed by the forth nucleotide content [23], although animal mitochondria deviated from Chargaff's second parity rule [24, 25] (Figure 1(a)). Vertebrate mitochondria overlapped with the high $\mathrm{C} / \mathrm{G}$ invertebrates, which have high $\mathrm{C}$ content (Figure 1(a)), indicating that both groups were descended from the same origin $[12,13]$, and that more highly evolved organisms seem to have a greater cytosine content [11]. Non-animal mitochondria and chloroplasts obeyed Chargaff's rules [23]. C contents in cellular organelles and chromosomal DNA vs G contents were expressed with linear regression lines, which crossed at a single point (Figure 1(a)). This is consistent with our previous findings [11, 12]. In addition, we found that nucleotide content relationships in viral DNA (Extended Data Table 1) were heteroskedastic (Figure 1(b)).

Based on the normalization of the four nucleotides $(G+C+T+A=1)$, the $G C$ content, $(G+C)$, is expressed by $\{1-(A+T)\}$, where $G C$ content $(G+C)$ and $A T$ content $(A+T)$ are completely linear, not only in chromosomal, non-animal mitochondrial, and chloroplast DNA, but also in animal mitochondrial DNA (Figure 1(c)). The same result was obtained for viral DNA (Figure 1(d)). Assuming irreversible divergence, it is generally thought that GC content increases along with biological evolution. Thus, the organelles that have the lowest GC content might be the most primitive. In the current study, the GC content of the mtDNA of the choanozoan M. brevicollis was the lowest among the samples examined. The GC content of the bacterium Streptomyces coelicolor was the highest of all the samples, although this organism was not the most evolved. Amongst the viruses examined, the GC content of Melanoplus sanguinipes Entomopoxvirus was the lowest, while that of Papio ursinus Cytomegalovirus was the highest (Figure 1(d)).

A previous study [11] stated that the $\mathrm{C}$ content of complete mitochondrial genomes reflects biological evolution better than the GC content. Based on the normalization of the four nucleotides, $\mathrm{G}+\mathrm{C}+\mathrm{A}+\mathrm{T}=$ $1, C=1-(G+A+T)$. Thus, $C$ content and $(G+A+T)$ are linear. In the current study, the lowest $C$ content was observed in $M$. brevicollis $\mathrm{mtDNA}$, while the highest $\mathrm{C}$ content was found in mtDNA from avian species Gallus gallus and Taeniopygia guttata, and primates $H$. sapiens, Pan paniscus, Pan troglodytes, and Gorilla gorilla (Figure 1(e)). Amongst the viral genomes, the C content of Mollivirus sibericum was the lowest, while that of De-Brazza's monkey virus was the highest (Figure 1(f)).

\subsection{Genome Evolution}

The complete genome is represented by four nucleotide contents based on more than a certain amount of randomly chosen fragments, as well as on completely linear fragments [26, 27]. Therefore, when the whole genome of bacterium Ureaplasma urealyticum (G; $0.131, \mathrm{C} ; 0.127$ ) was sequentially divided into nine equal fragments, the amounts of the four nucleotides in each fragment were quite similar (Figure 2(a)). This is consistent with our previous results, which indicated that a whole genome may be constructed from small units with similar amino acid compositions [26, 27]. Nucleotide content differences (i.e. $(\mathrm{G}-\mathrm{C})$ and $(\mathrm{A}-\mathrm{T})$ were reversed from positive to negative values in fragments 5 and 6 of the $U$. urealyticum genome (Figure $2(b)$ and Figure $2(c)$ ). The ratios of $(G-C) /(G+C)$ and 


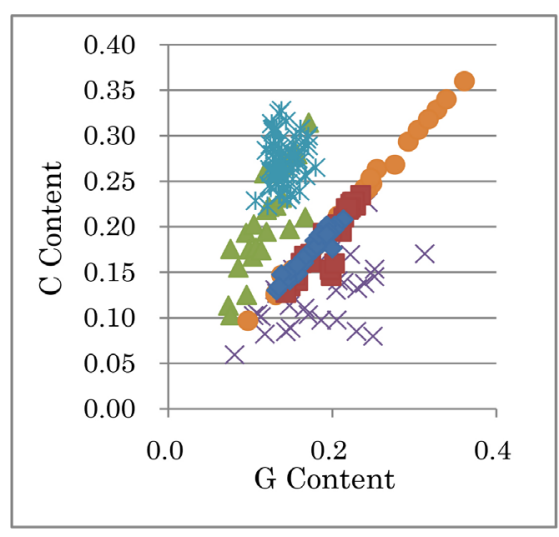

(a)

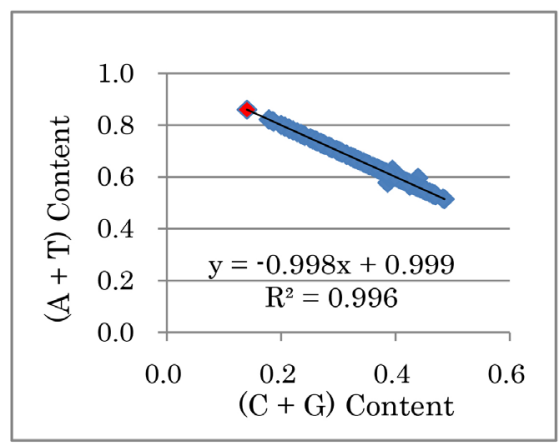

(c)

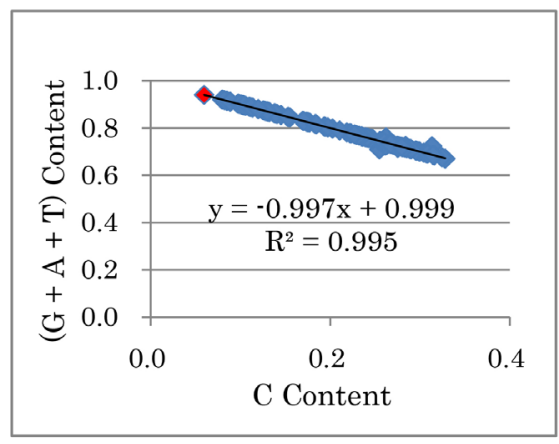

(e)

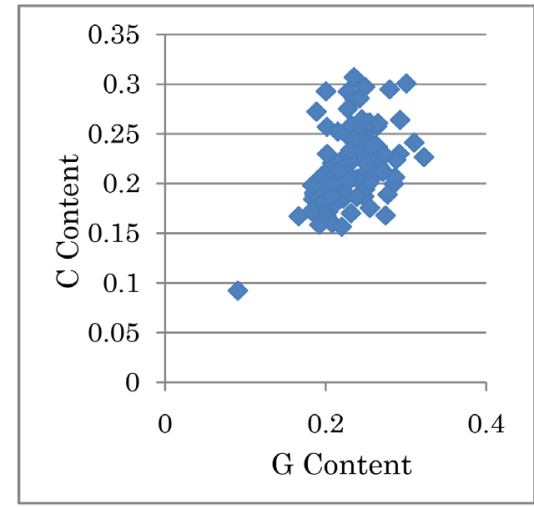

(b)

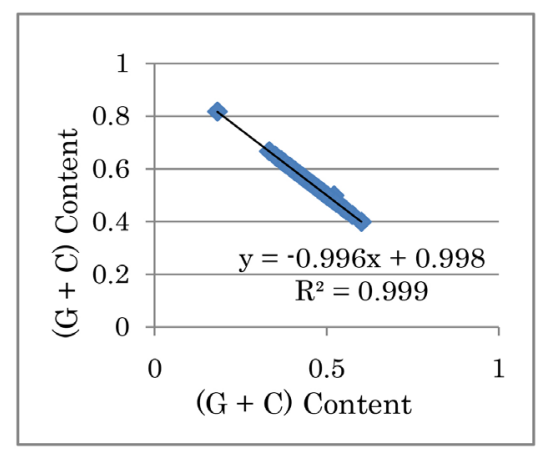

(d)

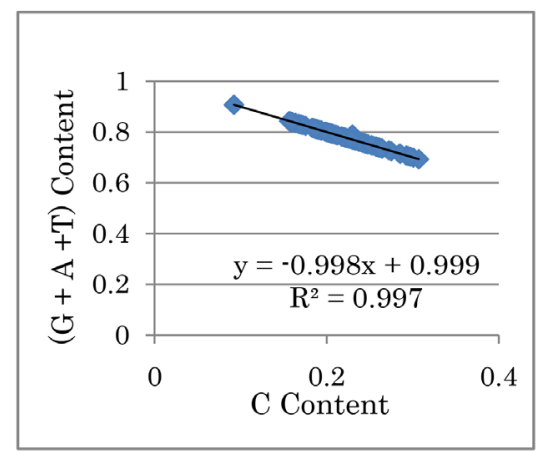

(f)

Figure 1. Regression lines. Left and right panels represent cellular organelles and viruses, respectively. Upper panels ( $a$ and $b$ ): horizontal and vertical axes represent $G$ and $C$ contents, respectively. Upper left panel: C content plotted against $\mathrm{G}$ content in vertebrate mitochondria (asterisk), high $\mathrm{C} / \mathrm{G}$ invertebrate mitochondria (triangle), low $\mathrm{C} / \mathrm{G}$ invertebrate mitochondria (cross), bacteria (circle), non-animal mitochondria, chloroplasts (diamond), and chromosomes (square). Red square represents Monosiga brevicollis mitochondrion. As the $p$-value based on the two regression lies representing high and low C/G animal mitochondria is 0.000 , these two lines are significantly different each other. There is no-significant difference among chromosomal, non-animal mitochondrial and chloroplast DNA, while these lines differ from those representing animal mitochondrial DNA. Right upper panel (a): C content plotted against $G$ content in viruses. Middle panels (c and d): Horizontal and vertical axes represent $(G+C)$ and $(A+T)$ contents, respectively. Lower panels $(e$ and $f)$ : Horizontal and vertical axes represent $(C)$ and $(G+A+T)$ contents, respectively. 


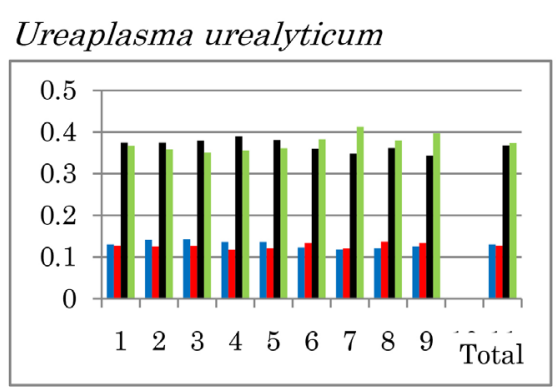

(a)

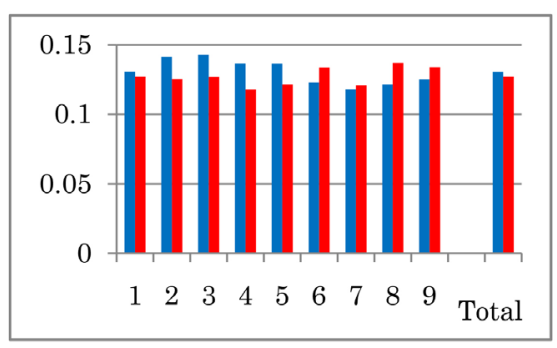

(b)

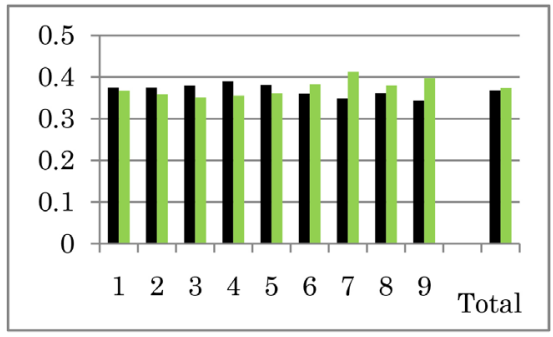

(c)

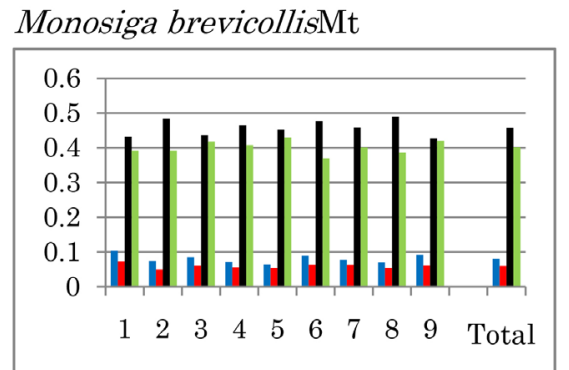

(d)

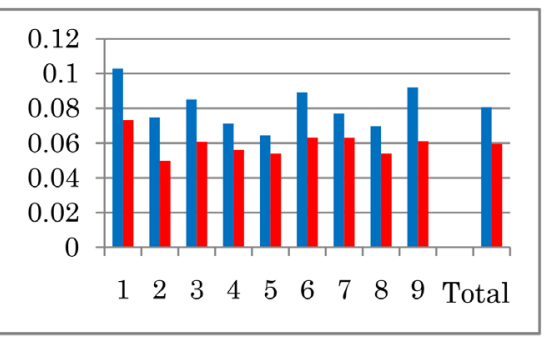

(e)

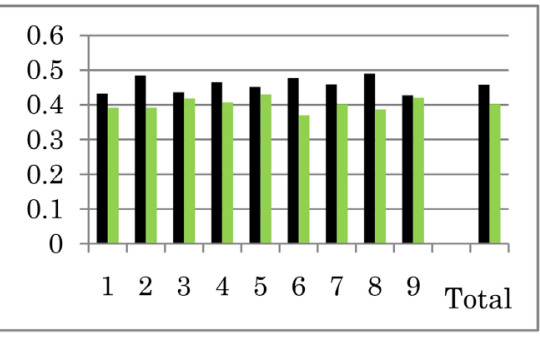

(f)

Figure 2. Nucleotide content was sequentially divided into nine fragments. Left side: Ureaplasma urealyticum mitochondrion, right side: Monosiga brevicollis mitochondrion. G: blue, C: red, A: black, and T: green. Vertical axis represents nucleotide content.

$(\mathrm{A}-\mathrm{T}) /(\mathrm{A}+\mathrm{T})$ are called the GC and AT skew, respectively [28]. The skew seems to be based on differences in replication processes between the leading and lagging strands [29]. In particular, replication of the lagging strand increases the probability of mutations as a result of the deamination of cytosine, and the inversion of nucleotide content differences reflects biological divergence. Similar phenomena are observed in mitochondria, which consist of heavy $(\mathrm{H})$ and light $(\mathrm{L})$ chains [30-32]. Plotting the GC skew vs. G content was used to classify animal mitochondria into two groups: high and low C/G [11]. In M. brevicollis mitochondria, the nine DNA fragments showed almost the same nucleotide contents (Figure 2(d)), as was observed in $U$. urealyticum (Figure 2(a)). However, GC and AT content difference inversions were not observed in $M$. brevicollis mtDNA (G: 0.081, C: 0.059) (Figure 2(e) and Figure 2(f)). Thus, the M. brevicollis mitochondrion might be more primitive than the $U$. urealyticum chromosome. These results clearly indicate that nucleotide content differences such as $(G-C)$ and $(A-T)$ reflect biological evolution. Therefore, the other nucleotide content differences, $(G-A, G-T, C-A$ and $C-T)$, were examined to determine whether or not these values reflect biological evolution.

\subsection{Organelle Evolution}

Complete mitochondrial genomes were investigated (Figure 3, left panel). To allow simple visual comparison of inter- and intra-species genome structures, genomes were sequential divided into three 


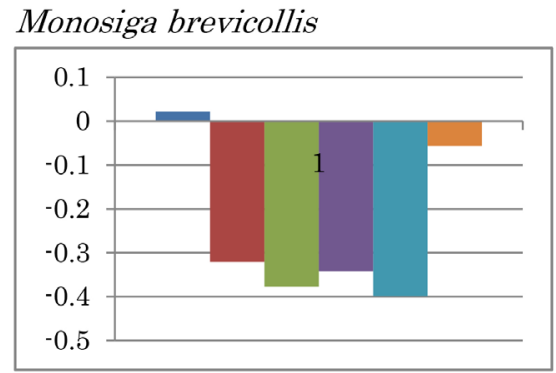

Polysphondylium pallidum

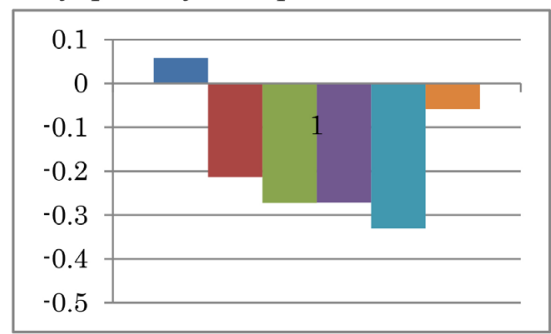

Dictyostelium discoideum

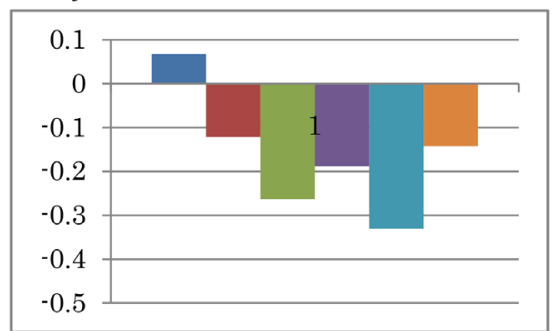

Reclinomonas americana

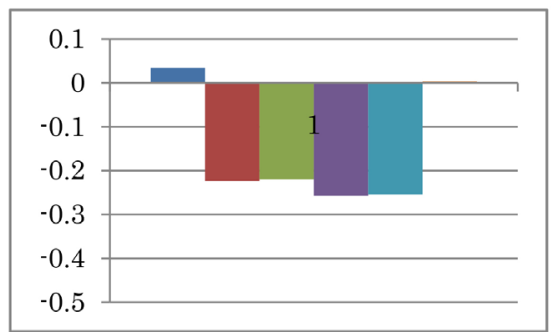

Monosiga brevicollis

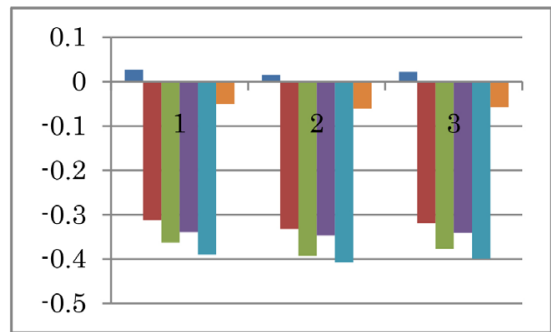

Polysphondylium pallidum

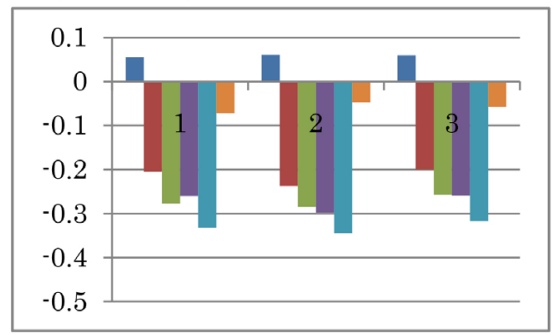

Dictyostelium discoideum

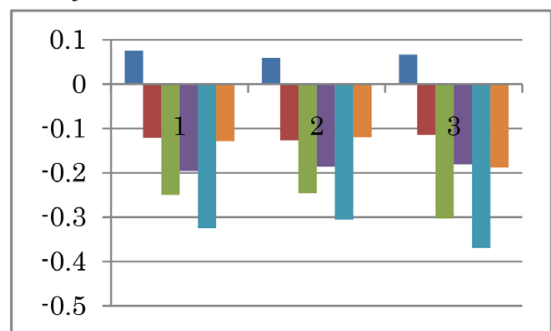

Reclinomonas americana

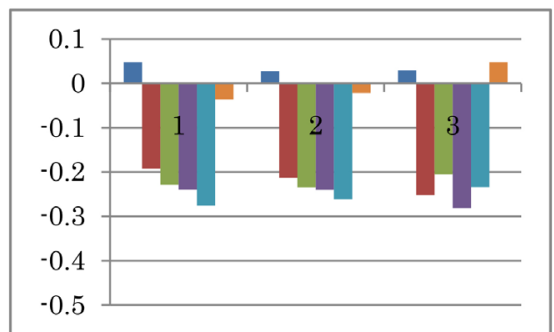

Figure 3. Nucleotide content differences in complete mitochondrial genomes (left side) and the three sequential fragments of each mitochondrial genome from 1 to 9 (right side). Left to right: (G - C), (G - T), (G - A), (C $-\mathrm{T}),(\mathrm{C}-\mathrm{A})$ and $(\mathrm{T}-\mathrm{A})$.

fragments throughout subsequent analyses, from which three separate patterns emerged. Six nucleotide content differences were observed among the mitochondria of the four species $(M$. brevicollis, $P$. pallidum, $D$. discoidium and $R$. americana) (Figure 3, right panels). The six nucleotide content patterns were conserved within the three fragments among the four species. No inversion of nucleotide content differences was observed in the mtDNA of $M$. brevicollis (G: 0.081, C: 0.059), the mycetozoan Polysphondylium pallidum (G: 0.143, C: 0.085), or Dictyostelium discoideum (G: 0.171, C: 0.104) (Figure 3), although differences in $(\mathrm{G}-\mathrm{C})$ and $(\mathrm{T}-\mathrm{A})$ values for $M$. brevicollis mtDNA were the lowest amongst these species. Based on genome sequencing, choanoflagellates are most closely related to animals [33]. As the nucleotide content difference patterns of the three fragments were almost identical for these three species, their nucleotide distributions were judged to be homogeneous, indicating nucleotide content symmetry. Thus, these 
mitochondria are likely to be primitive. Consistent results were obtained from Ward's clustering analysis using amino acid compositions predicted from complete mitochondrial genomes as traits [11]. These findings indicate that the $M$. brevicollis mitochondrion is the most primitive among the three. In contrast, AT inversion was observed in the third fragment of Reclinomonas americana mtDNA (G: 0.148, C: 0.114), which has previously been proposed as a mitochondrial ancestor [8]. However, differences in ( $G-C)$ and ( $\mathrm{T}-\mathrm{A}$ ) values in $R$. americana mtDNA were smaller than those in the mtDNA of the previous three organisms. Nucleotide content inversion causes significant differences in nucleotide content patterns as a result of unsymmetrical nucleotide content. Thus, the $R$. americana mitochondrion is probably more evolved than the former three mitochondria. In addition, AT inversion occurred in the following more highly evolved organisms: Mollusca species, squid (Todarodes pacificus), octopus (Octopus vulgaris), Echinodermata species, sea urchin (Paracentrotus lividus), water flea (Daphnia pulex), hermit crab (Pagurus longicarpus), and Humboldt squid (Dosidicus gigas) (Extended Data Figure 1). In addition, large positive $(\mathrm{G}-\mathrm{A})$ values in the three fragments were observed in Paragonimus westermani, while large positive $(\mathrm{G}-\mathrm{C})$ and $(\mathrm{A}-\mathrm{T})$ values in the three fragments were observed for the mtDNA of representatives of the following phyla: Cnidaria (Pavona clavus), Platyhelminthes (Schistosoma mansoni), Porifera (Geodia neptuni), Arthropoda (Tigriopus californicus), and Chordata (Branchiostoma belcheri) (Extended Data Figure 1).

A positive $(\mathrm{C}-\mathrm{T})$ value was characteristically observed in the three fragments of Echinodermata species Acanthaster planci, the second and third fragments of Mollusca species Haliotis rubra, and in the first fragment of Mollusca species Lampsilis ornata. CT inversion occurred in $H$. rubra and $L$. ornata mtDNA (Extended Data Figure 1). The nucleotide content difference patterns of the mtDNA of hemichordates Saccoglossus kowalevskii and Balanoglossus carnosus differed from each other. Both AT and CT inversions occurred in the first mtDNA fragment of $S$. kowalevskii, while large positive $(\mathrm{C}-\mathrm{T})$ and $(\mathrm{C}-\mathrm{A})$ value differences occurred in the second and third fragments. AC and AT inversions were observed in $B$. carnosus mtDNA (Extended Data Figure 1). Neither nucleotide inversion nor positive nucleotide differences were observed in the mtDNA of deuterostom, Xenoturbella bocki.

In the mtDNA of primate species $H$. sapiens, $P$. troglodytes, G. gorilla, Macaca mulatta, Daubentonia madagascariensis, Nycticebus coucang, and Tupaia belangeri, nucleotide content difference patterns were quite similar in the first four species, and large positive increases in $(\mathrm{C}-\mathrm{T})$ differences in the three fragments clearly indicated evolutionary divergence (Figure 4). The positive $(C-T)$ differences in all three fragments were characteristic of these four primate mitochondria, while positive increases in $(C-T)$ values were only observed in the third fragment of $N$. coucang and $T$. belangeri mtDNA. In contrast, nucleotide content difference patterns of the prosimian Lemur catta completely differed from those of the primates, although TA inversion was observed in the second fragment. The primate mtDNA nucleotide content patterns were also completely different from that of hemichordate $B$. carnosus, although their $\mathrm{C}$ contents were the highest among all organisms examined [11]. This finding indicates that mitochondrial structures respect epigenomic evolutionary functions.

The mitochondria of other vertebrates (Extended Data Text.), rodents (Extended Data Figure 2(a)), ocean-dwelling mammals, cetaceans, aves (Extended Data Figure 2(b)), amphibians (Extended Data Figure 2(c)), reptiles (Extended Data Figure 2(d)), and fishes (Extended Data Figure 2(e) and Extended Data Figure 2(f)) were also examined. In these organelles, differences in $(G-C)$ and $(A-T)$ or in other nucleotide inversions, as well as GC and AT inversions, increased along with evolution. Consistent results were also obtained from non-animal mitochondria and chloroplasts (Extended Data Figure 3), as well as prokaryotes (Extended Data Figure 4). In the microsporidian protozoan Encephalitozoon cuniculi, GC and AT inversions, as well as other nucleotide content inversions, were observed (Extended Data Figure 5).

\subsection{Virus Evolution}

The $M$. sanguinipes Entomopoxvirus genome had the lowest $\mathrm{G}$ content among the viruses examined (Figure 1), and AT inversion was also observed (Extended Data Figure 6). In P. ursinus Cytomegalovirus, 


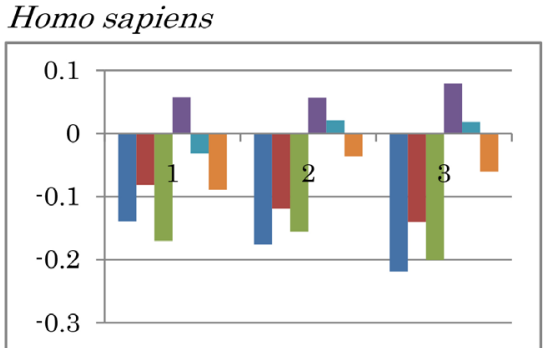

Pan troglodytes

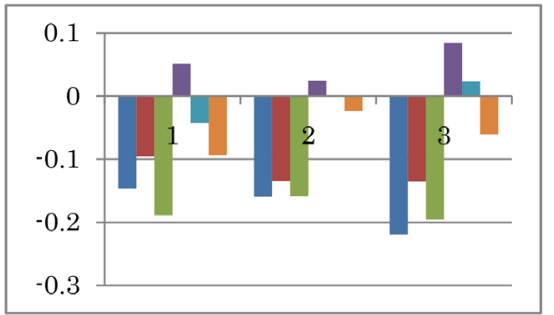

Gorilla gorilla

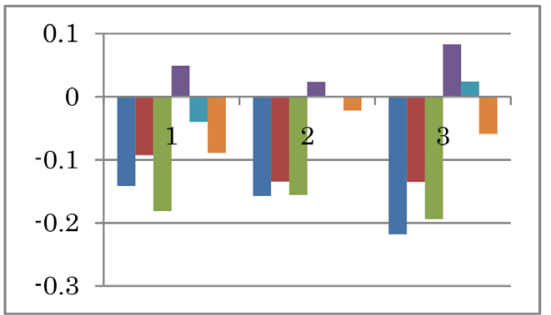

Macaca mulatta

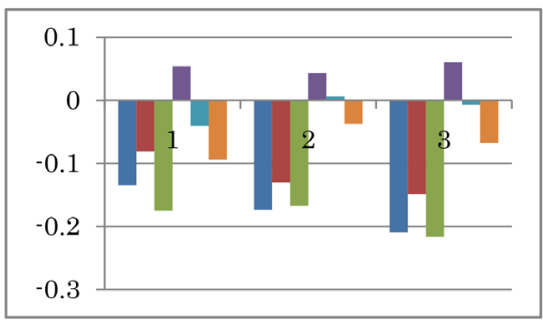

Daubentonia madagascariensis
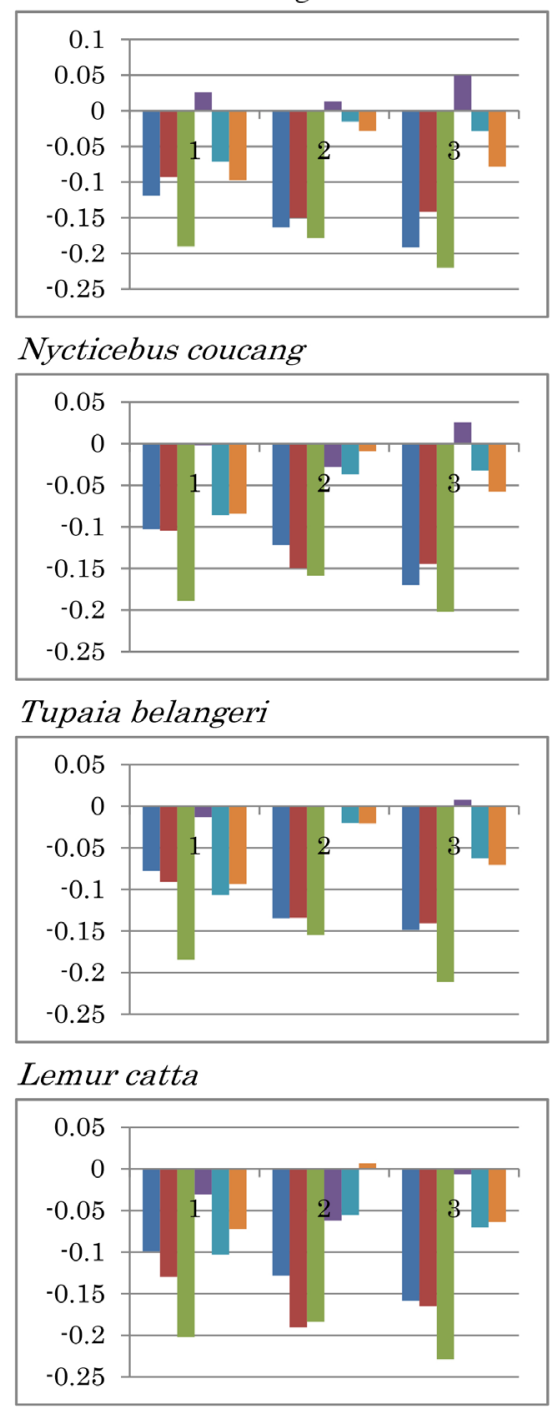

Figure 4. Nucleotide differences in the three fragments of primate mitochondrial genome from 1 to 3 . Left to right: $(G-C),(G-T),(G$ - A), (C - T), (C -A) and (T - A).

whose GC content was the highest, both GC and AT inversions occurred. Mollivirus sibercum, which had the lowest C content, showed both GC and AT inversions, while DeBrazza's monkey virus 1 showed both GA and GT inversions.

Ebola haemorrhagic fever, caused by the Ebola virus, can be fatal in humans. The Reston, Sudan, and Zaire strains did not show any nucleotide inversion in the three genome fragments (Figure 5). In the Tai Forest and Bundibugyo strains, however, CT inversion was clearly observed in the first fragment, and was accompanied by a decrease in GT content difference. These nucleotide content differences corresponded to the GC contents of the strains: Reston (G: 0.198, C: 0.210) [34], Sudan (G: 0.198, C: 0.216) [35], Zaire (G: 0.198, C: 0.213) [36], Tai Forest (G: 0.192, C: 0.231) [37], and Bundibugyo (G: 0.192, C: 0.228) [37]. An increase in $\mathrm{C}$ content and decrease in $\mathrm{G}$ content were observed in the Tai Forest and Bundibugyo strains. The calculated GC contents for the strains were: 0.406 (Reston), 0.411 (Zaire), 0.414 (Sudan), 0.420 (Bundibugyo), and 0.423 (Tai Forest). These results may indicate that Ebola virus evolution occurred over a short period of time. 


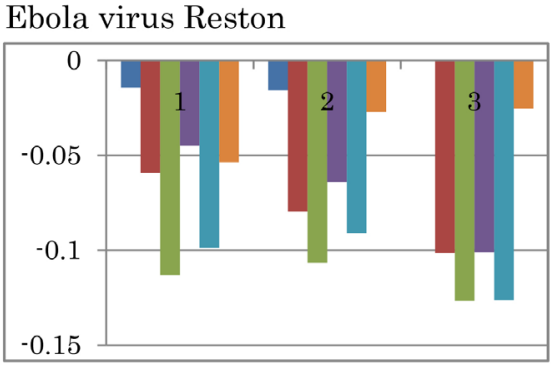

Ebola virus Sudan

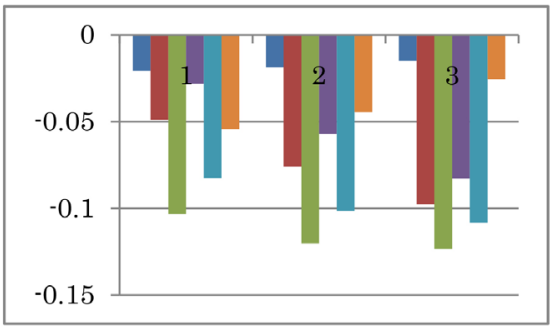

Ebola virus Zaire

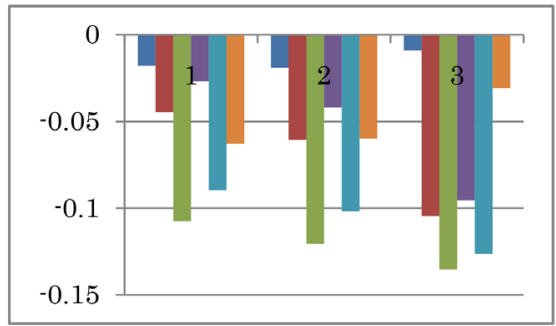

Ebola virus Bundibugyyo

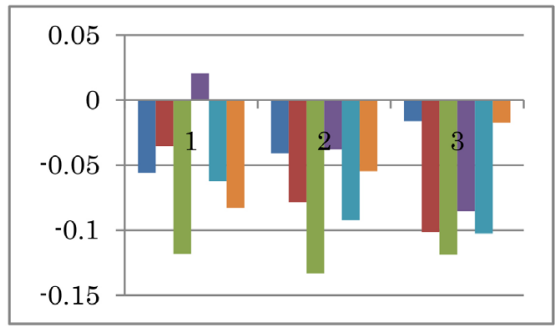

Ebola virus Tai Forest

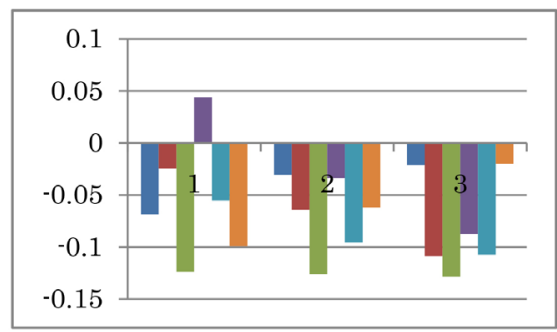

Figure 5. Nucleotide content differences in the three fragments of Ebola virus genomes from 1 to 3 . Left to right: $(G-C),(G-T),(G-A),(C-$ $\mathrm{T}),(\mathrm{C}-\mathrm{A})$ and $(\mathrm{T}-\mathrm{A})$.

\subsection{Interspecies Evolution}

Nucleotide content differences were calculated in vertebrate mitochondria (Extended Data Figure 7(a)), invertebrate mitochondria (Extended Data Figure 7(b)), non-animal mitochondria (Extended Data Figure $7(\mathrm{c})$ ), chloroplasts (Extended Data Figure $7(\mathrm{~d})$ ) and nuclear DNA (Extended Data Figure $7(\mathrm{e})$ ).

\subsection{Definitive Universal Equation}

Plotting $(\mathrm{X}-\mathrm{Y}) /(\mathrm{X}+\mathrm{Y})$ against $(\mathrm{X}-\mathrm{Y})$, the following linear relationship was obtained in mitochondria, chloroplasts, and chromosomes (Figure 6(a)), and viruses (Figure 6(b)): $(\mathrm{X}-\mathrm{Y}) /(\mathrm{X}+\mathrm{Y})=\mathrm{a}(\mathrm{X}-\mathrm{Y})$ $+\mathrm{b}$, where $\mathrm{X}$ and $\mathrm{Y}$ are nucleotide contents, and (a) and (b) are constants. As (b) was almost null and (a) was $\sim 2.0,(\mathrm{X}-\mathrm{Y}) /(\mathrm{X}+\mathrm{Y}) \approx 2.0(\mathrm{X}-\mathrm{Y})$. In these genome analyses, which are independent of Chargaff's parity rules (Extended Data Figure 8, left panels), the values of (a) for $(G, C),(G, A),(G, T),(C, T),(C$, $\mathrm{A})$ and $(\mathrm{A}, \mathrm{T})$ were $2.5858,1.85558,1.9908,1.9771,1.9968$ and 1.5689 , respectively. Based on these results, $(G+C),(G+A),(G+T),(C+A),(C+T)$ and $(A+T)$ were $0.39,0.54,0.50,0.51,0.50$ and 0.64 , respectively. In virus genome analyses (Extended Data Figure 8, right panels), the constant values for (a) were $1.9-2.1$, and the values for $(\mathrm{X}+\mathrm{Y})$ were $0.47-0.53$. In contrast, in the normalization of nucleotide contents $(\mathrm{G}+\mathrm{C}+\mathrm{A}+\mathrm{T}=1)$, as $(\mathrm{G}=\mathrm{C})$ and $(\mathrm{A}=\mathrm{T})$ based on Chargaff's parity rules, $(2 \mathrm{G}+2 \mathrm{~A}=1)$ is obtained. This equation is altered to $(G+A=0.5)$. This value is consistent with the value obtained above from genome analyses. Similarly, $(G+T=0.5),(C+A=0.5)$ and $(C+T=0.5)$, although $(G+C)$ and $(A+T)$ cannot be determined. Therefore, the four nucleotide contents are expressed by the following regression lines, 
(a) Mitochondria, Chloroplasts, Chromosomes

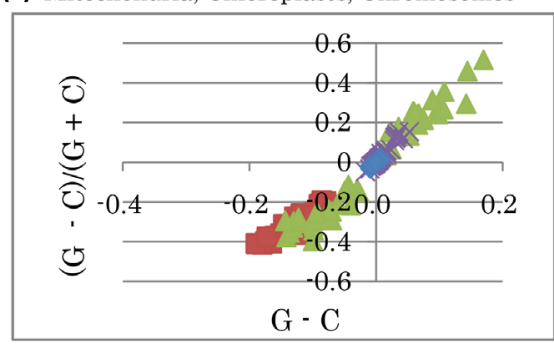

(b) Viruses

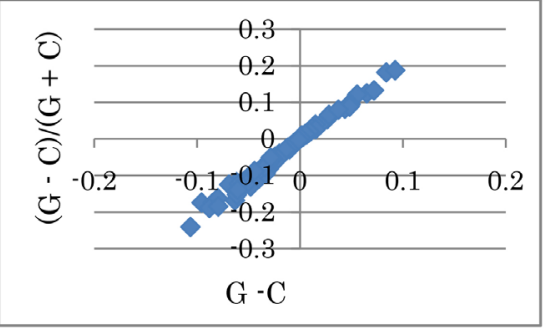

(c) Random numbers

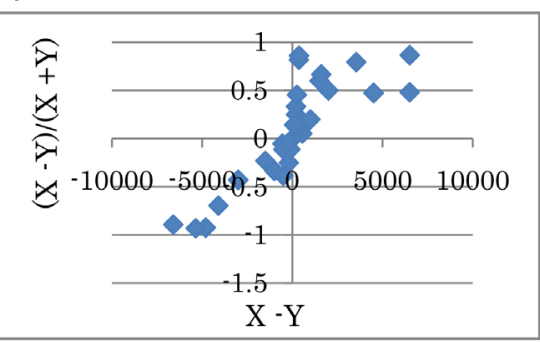

(a')

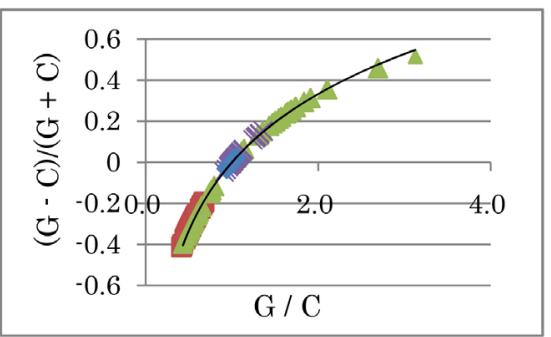

(b')

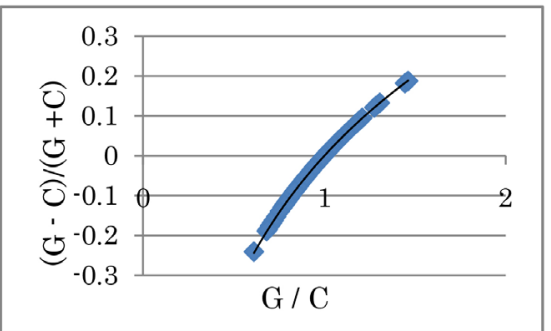

(c')

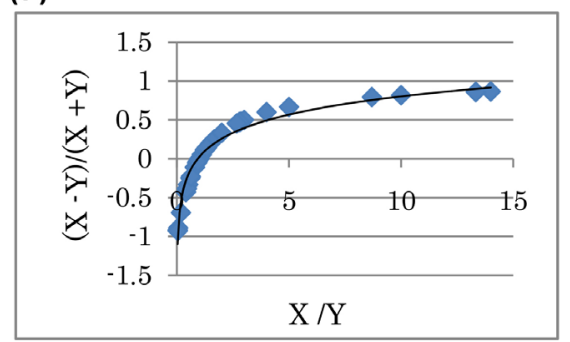

Figure 6. Universal rules. Left side: relationship between $(G-C)$ and $(G-C) /(G+C)$, expressed by a linear regression, and right side: relationship between $(G / C)$ and $(G-C) /(G+C)$, expressed by a logarithmic function. The random numbers were not normalized.

plotted against $\mathrm{G}$ content: $\mathrm{A}=0.5-\mathrm{G}, \mathrm{T}=0.5-\mathrm{G}, \mathrm{C}=\mathrm{G}$ and $(\mathrm{G}=\mathrm{G})$. Lines $\mathrm{G}$ and $\mathrm{C}$ overlap, as do lines $\mathrm{A}$ and $\mathrm{T}$, and the former line is symmetrical to the latter against line $(y=0.25)$. The intercepts of lines $\mathrm{G}$ and $\mathrm{C}$ are close to the origin, while those of lines $\mathrm{A}$ and $\mathrm{T}$ are close to 0.5 at the vertical and horizontal axes. All organisms from bacteria to $H$. sapiens are located on the diagonal lines of a 0.5 square, termed the "Diagonal Genome Universe", using the normalized values that obey Chargaffs parity rules [27]. These relationships lead to $(\mathrm{G}$ or $\mathrm{C})+(\mathrm{A}$ or $\mathrm{T})=0.5$. The present results indicate that a linear regression line equation, $(\mathrm{X}-\mathrm{Y}) /(\mathrm{X}+\mathrm{Y})=\mathrm{a}(\mathrm{X}-\mathrm{Y})+\mathrm{b}$, universally represents all normalised values, including the values deviating from Chargaff's parity rules. This newly discovered equation clearly reflects not only Chargaff's parity rules, based on hydrogen bonding between two nucleotides, but also natural rule.

A linear regression line was not obtained when using randomly chosen value (Figure 6(c)). Furthermore, plotting $(\mathrm{X}-\mathrm{Y}) /(\mathrm{X}+\mathrm{Y})$ against $(\mathrm{X} / \mathrm{Y})$, the following logarithmic function was obtained for all tested genomes as well as when using randomly chosen values (Figure $\left.6\left(\mathrm{a}^{\prime}\right)-\left(\mathrm{c}^{\prime}\right)\right):(\mathrm{X}-\mathrm{Y}) /(\mathrm{X}+\mathrm{Y})=$ $\mathrm{aln}(\mathrm{X} / \mathrm{Y})+\mathrm{b}$. As (b) was almost null and (a) was $\sim 0.5,(\mathrm{X}-\mathrm{Y}) /(\mathrm{X}+\mathrm{Y}) \approx 0.5 \ln (\mathrm{X} / \mathrm{Y})$. The ratio between two values, $(\mathrm{X} / \mathrm{Y})$, can be expressed by a logarithmic function, $\sim 0.5 \ln (\mathrm{X} / \mathrm{Y}) \approx(\mathrm{X}-\mathrm{Y}) /(\mathrm{X}+\mathrm{Y})$. Plotting the GC skew vs. G content, animal mitochondria were classified into two groups: high and low C/G [11]. This fact indicates that the ratio $\mathrm{C} / \mathrm{G}$ and the GC skew are evolutionarily related to each other. Any change can be expressed universally by a definitive logarithmic function, $(\mathrm{X}-\mathrm{Y}) /(\mathrm{X}+\mathrm{Y})=\mathrm{a} \ln (\mathrm{X} / \mathrm{Y})+\mathrm{b}$. The present results indicate that cellular organelle evolution is strictly controlled under these characteristic rules, 

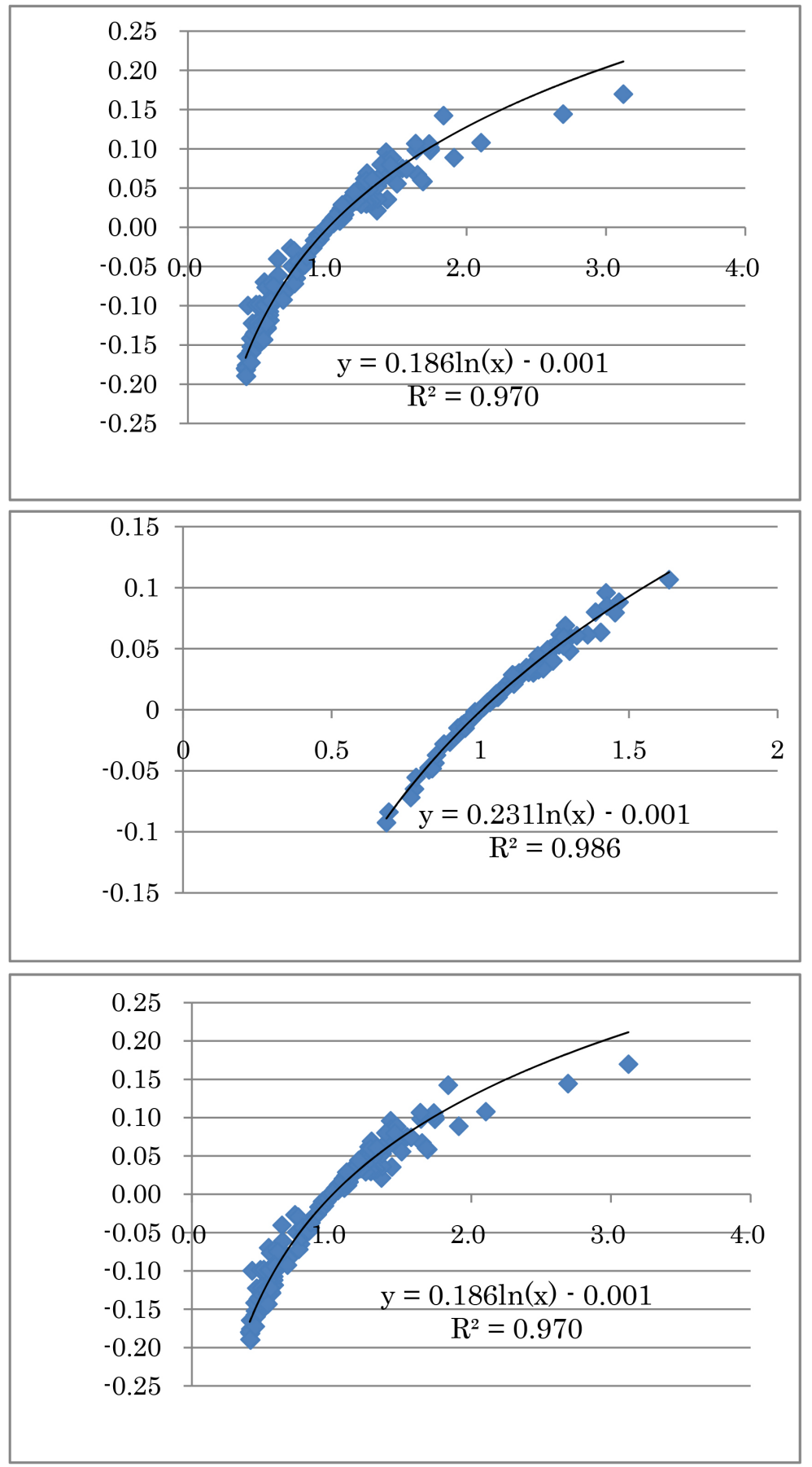

Figure 7. Universal rule governing genome evolution from viruses to $H$. sapiens. Upper pane: cellular organelles, middle panel: viruses, and lower panel: cellular organelles plus viruses.

although non-animal mitochondria, chloroplasts, and chromosomes are controlled under Chargaff's parity rule [17]. The present study clearly shows that biological evolution, which seems to be based on complicated processes, is governed by simple universal equations. In fact, the codon [22] and genome evolution [23] were expressed in complete genomes by linear formulas, and it has been shown that a whole genome 
is constructed with gene assembly of small units with a similar amino acid composition [26], as shown in Figure 2 and Extended Data Figure 5.

\section{CONCLUSION}

Our findings showed that the most primitive extant ancestor of all living organisms is the M. brevicollis mitochondrion. In the normalised genome values, the relationship between the nucleotide difference, $(\mathrm{X}-\mathrm{Y})$, and $(\mathrm{X}-\mathrm{Y}) /(\mathrm{X}+\mathrm{Y})$, including biological evolution, can be expressed definitively by a linear regression line: $(\mathrm{X}-\mathrm{Y}) /(\mathrm{X}+\mathrm{Y})=\mathrm{a}(\mathrm{X}-\mathrm{Y})+\mathrm{b}$, where $(\mathrm{a} \approx 2.0)$ and $(\mathrm{b} \approx 0)$ are constants. $(\mathrm{X}+\mathrm{Y})=$ approximately 0.5 . The nucleotide difference, $(\mathrm{X}-\mathrm{Y})$, is generally expressed by a linear regression line that crosses " 0 " at $(\mathrm{X}=\mathrm{Y})$, representing no evolution. In addition, the relationship between the ratio $(\mathrm{X} / \mathrm{Y})$ and $(\mathrm{X}-\mathrm{Y}) /(\mathrm{X}+\mathrm{Y})$ can be expressed definitively by a logarithmic function, $(\mathrm{X}-\mathrm{Y}) /(\mathrm{X}+\mathrm{Y})=\mathrm{a} \ln (\mathrm{X} / \mathrm{Y})+\mathrm{b}$, where $(\mathrm{a} \approx 0.5)$ and $(\mathrm{b} \approx 0)$ are constants. The relationship between the skew " $(\mathrm{X}-\mathrm{Y}) /(\mathrm{X}+\mathrm{Y})$ " and the ratio $(\mathrm{Y} / \mathrm{X})$ is universally expressed by a logarithmic line that crosses " 1 " at $(\mathrm{X}=\mathrm{Y})$, representing no change. As the left sides, $(\mathrm{X}-\mathrm{Y}) /(\mathrm{X}+\mathrm{Y})$, are equal in both equations, $2.0(\mathrm{X}-\mathrm{Y}) \approx 0.5 \ln (\mathrm{X} / \mathrm{Y})$. Finally, $(\mathrm{X}-\mathrm{Y}) \approx 0.25 \ln (\mathrm{X} / \mathrm{Y})$ using the normalized values from viruses to $H$. sapiens (Figure 7).

\section{CONFLICTS OF INTEREST}

The author declares no conflicts of interest regarding the publication of this paper.

\section{REFERENCES}

1. Tsuji, G., Fujii, S., Sunami, T. and Yomo, T. (2016) Sustainable Proliferation of Liposomes Compatible with Inner RNA Replication. Proceedings of National Academy of Sciences of United States of America, 113, 590-595. https://doi.org/10.1073/pnas.1516893113

2. Schopf, J.W. and Barghoorn, E.S. (1967) Alga-Like Fossils from the Early Precambrian of South Africa. Science, 3774, 508-512. https://doi.org/10.1126/science.156.3774.508

3. Nagy, B., Zumberge, J.E. and Nagy, L.A. (1975) Abiotic, Graphitic Microstructures in Micaceous Metaquartzite about 3760 Million Years Old from Southwestern Greenland: Implications for Early Precambrian Microfossils. Proceedings of National Academy of Sciences of United States of America, 72, 1206-1209. https://doi.org/10.1073/pnas.72.3.1206

4. Noffke, N., Christian, D., Wacey, D. and Hazen, R.M. (2013) Microbially Induced Sedimentary Structures Recording an Ancient Ecosystem in the ca. 3.48 Billion-Year-Old Dresser Formation, Pilbara, Western Australia. Astrobiology, 13, 1103-1124. https://doi.org/10.1089/ast.2013.1030

5. Schopf, J.W. (2006) Fossil Evidence of Archaean Life. Philosophical Transactions of the Royal Society B Biological Sciences, 361, 869-885. https://doi.org/10.1098/rstb.2006.1834

6. Gray, M.W. (1992) The Endosymbiont Hypothesis Revisited. International Review of Cytology, 141, 233-357. https://doi.org/10.1016/S0074-7696(08)62068-9

7. Ku, C., Nelson-Sathi, S., Roettger, M., Sousa, F.L., Lockhart, P.J., Bryant, D., et al. (2015) Endosymbiotic Origin and Differential Loss of Eukaryotic Genes. Nature, 524, 427-432. https://doi.org/10.1038/nature14963

8. Andersson, S.G., Zomorodipour, A., Andersson, J.O., Sicheritz-Pontén, T., Alsmark, U.C., Podowski, R.M., et al. (1998) The Genome Sequence of Rickettsia prowazekii and the Origin of Mitochondria. Nature, 396, 133-140. https://doi.org/10.1038/24094

9. Thrash, J.C., Boyd, A., Huggett, M.J., Grote, J., Carini, P., Yoder, R.J., et al. (2011) Phylogenomic Evidence for a Common Ancestor of Mitochondria and the SAR11 Clade. Scientific Reports, 1, 13. https://doi.org/10.1038/srep00013 
10. Sorimachi, K. and Okayasu, T. (2014) Classification of Non-Animals and Invertebrates Based on Amino Acid Composition of Complete Mitochondrial Genomes. International Journal of Biology, 6, 1-16.

11. Sorimachi, K. (2015) Origine of Life in the Ocean: Direct Derivation of Mitochondria from Primitive Organisms Based on Complete Genomes. Current Chemical Biology, 9, 23-35. https://doi.org/10.2174/2212796809666150911201738

12. Sorimachi, K. (2010) Genome Data Provides Simple Evidence for a Single Origin of Life. Natural Science, 2, 519-525.

13. Sorimachi, K., Okayasu, T., Ohhira, S., Fukasawa, I. and Masawa, N. (2012) Evidence for the Independent Divergence of Vertebrate and High C/G Ratio Invertebrate Mitochondria from the Same Origin. Natural Science, 4, 479-483.

14. Sorimachi, K. (1999) Evolutionary Changes Reflected by the Cellular Amino Acid Composition. Amino Acids, 17, 207-226. https://doi.org/10.1007/BF01361883

15. Sorimachi, K., Itoh, T., Kawarabaysi, Y., Okayasu, T., Akimoto, K. and Niwa, A. (2001) Conservation of the Basic Pattern of Cellular Amino Acid Composition during Biological Evolution and the Putative Amino Acid Composition of Primitive Life Forms. Amino Acids, 21, 393-399. https://doi.org/10.1007/s007260170004

16. Chargaff, E. (1950) Chemical Specificity of Nucleic Acids and Mechanism of Their Enzymatic Degradation. EXperientia, 6, 201-209. https://doi.org/10.1007/BF02173653

17. Rundner, R., Karkas, J.D. and Chargaff, E. (1968) Separation of B. subtilis DNA into Complementary Strands. 3. Direct Analysis. Proceedings of the National Academy of Sciences, 60, 921-922.

https://doi.org/10.1073/pnas.60.3.921

18. Sorimachi, K. (2009) A Proposed Solution to the Historic Puzzle of Chargaff's Second Parity Rule. The Open Genomics Journal, 2, 12-14. https://doi.org/10.2174/1875693X00902010012

19. Sorimachi, K., Okayasu, T. and Ohhira, S. (2015) Normalization of Complete Genome Characteristic: Application to Evolution from Primitive Organisms to Homo sapiens. Current Genomics, 16, 99-106. https://doi.org/10.2174/1389202916666150119215716

20. Sorimachi, K. (2014) Indices of Whole Genome Characteristics Based on Amino Acid or Nucleotide Content Ratios: Evolution from Primitive Organisms to Homo sapiens. Journal of Chemical Engineering and Chemistry Research, 1, 302-312.

21. Mitchell, D. and Bridge, R. (2006) A Test of Chargaffs Second Rule. Biochemical and Biophysical Research Communications, 340, 90-94. https://doi.org/10.1016/j.bbrc.2005.11.160

22. Sorimachi, K. and Okayasu, T. (2008) Codon Evolution Is Governed by Linear Formulas. Amino Acids, 34, 345-350. https://doi.org/10.1007/s00726-007-0024-3

23. Sorimachi, K. and Okayasu, T. (2008) Universal Rules Governing Genome Evolution Expressed by Linear Formulas. Open Current Genomics, 1, 33-43. https://doi.org/10.2174/1875693X00801010033

24. Nikolaou, C. and Almirantis, Y. (2006) Deviations from Chargaff's Second Parity Rule in Organellar DNA Insights into the Evolution of Organellar Genomes. Gene, 381, 34-41. https://doi.org/10.1016/j.gene.2006.06.010

25. Bell, S.J. and Forsdyke, D.R. (1999) Deviations from Chargaff's Second Parity Rule Correlate with Direction of Transcription. Journal of Theoretical Biology, 197, 63-76.

26. Sorimachi, K. and Okayasu, T. (2003) Gene Assembly Consisting of Small Units with Similar Amino Acid Composition in the Saccharomyces cerevisia. Mycoscience, 44, 415-417. https://doi.org/10.1007/S10267-003-0131-2

27. Sorimachi, K. (2010) Evolution Based on Genome Structure: The "Diagonal Genome Universe". Natural 
Science, 2, 1104-1112.

28. Lobry, J.R. (1996) Asymmetric Substitution Patterns in the Two DNA Strands of Bacteria. Molecular Biology and Evolution, 13, 660-665. https://doi.org/10.1093/oxfordjournals.molbev.a025626

29. Tillier, E.R. and Collins, R.A. (2000) The Contributions of Replication Orientation, Gene Direction, and Signal Sequences to Base-Composition Asymmetries in Bacterial Genomes. Journal of Molecular Evolution, 50, 249-257. https://doi.org/10.1007/s002399910029

30. Anderson, S., Bankier, A.T., Barrell, B.G., de Bruijn, M.H., Coulson, A.R., Drouin, J., et al. (1981) Sequence and Organization of the Human Mitochondrial Genome. Nature, 290, 457-465. https://doi.org/10.1038/290457a0

31. Fonceca, M.M., Harris, D.J. and Posada, D. (2014) The Inversion of the Control Region in Three Mitogenomes Provides Further Evidence for an Asymmetric Model of Vertebrate mtDNA Replication. PLoS ONE, 9, e106654. https://doi.org/10.1371/journal.pone.0106654

32. Seligmann, H. (2012) Coding Constraints Modulate Chemically Spontaneous Mutational Replication Gradients in Mitochondrial Genomes. Current Genomics, 13, 37-54. https://doi.org/10.2174/138920212799034802

33. King, N., Westbrook, M.J., Young, S.L., Kuo, A., Abedin, M., Chapman, J., et al. (2008) The Genome of the Choanoflagellates Monosiga brevicollis and the Origin of Metazoans. Nature, 451, 783-788. https://doi.org/10.1038/nature06617

34. Groseth, A., Stroher, U., Theriault, S. and Feldmann, H. (2002) Molecular Characterization of an Isolate from the 1989/90 Epizootic of Ebola Virus Reston among Macaques Imported into the United States. Virus Research, 87, 155-163. https://doi.org/10.1016/S0168-1702(02)00087-4

35. Sanchez, A. and Rollin, P.E. (2005) Complete Genome Sequence of an Ebola Virus (Sudan Species) Responsible for a 2000 Outbreak of Human Disease in Uganda. Virus Research, 113, 16-25. https://doi.org/10.1016/j.virusres.2005.03.028

36. Volchkov, V.E., Volchkova, V.A., Chepurnov, A.A., Blinov, V.M., Dolnik, O., Netesov, S.V., et al. (1999) Characterization of the L Gene and 5' Trailer Region of Ebola Virus. Journal of General Virology, 80, 355-362. https://doi.org/10.1099/0022-1317-80-2-355

37. Towner, J.S., Sealy, T.K., Khristova, M.L., Albariño, C.G., Conlan, S., Reeder, S.A., et al. (2008) Newly Discovered Ebola Virus Associated with Hemorrhagic Fever Outbreak in Uganda. PLOS Pathogens, 4, e1000212. https://doi.org/10.1371/journal.ppat.1000212

38. Jenkins, P.D., Kilpatorick, C.W., Robinson, M.F. and Timmins, R.J. (2004) Morphological and Molecular Investigations of a New Family, Genus and Species of Rodent (Mammalia: Rodentia: Hystricognatha) from Lao PDR. Systematics and Biodiversity, 2, 419-454. https://doi.org/10.1017/S1477200004001549

39. Dawson, M.R., Marivaux, L., Li, C.K., Beard, K.C. and Métais, G. (2006) Laonastes and the "Lazarus Effect" in Recent Mammals. Science, 311, 1456-1458. https://doi.org/10.1126/science.1124187

40. Gaudin, T.J., Emry, R.J. and Wible, J.R. (2009) The Phylogeny of Living and Extinct Pangolins (Mammalia, Pholidota) and Associated Taxa: A Morphology Based Analysis. Journal of Mammalian Evolution, 16, 235-305.

https://doi.org/10.1007/s10914-009-9119-9

41. Gatesy, J., Hayashi, C., Cronin, M.A. and Arctander, P. (1996) Evidence from Milk Casein Genes That Cetaceans Are Close Relatives of Hippopotamid Artiodactyls. Molecular Biology and Evolution, 13, 954-963.

https://doi.org/10.1093/oxfordjournals.molbev.a025663

42. Ursing, B.M. and Arnason, U. (1998) Analyses of Mitochondrial Genomes Strongly Support a Hippopotamus-Whale Clade. Proceedings of the Royal Society B: Biological Sciences, 265, 2251-2255. https://doi.org/10.1098/rspb.1998.0567

43. Sorimachi, K. and Okayasu, T. (2013) Phylogenetic Tree Construction Based on Amino Acid Composition and 
Nucleotide Content of Complete Vertebrate Mitochondrial Genomes. IOSR Journal of Pharmacy, 3, 51-60.

44. Session, A.M., Uno, Y., Kwon, T., Chapman, J.A., Toyoda, A., Takahashi, S., et al. (2016) Genome Evolution in the Allotetraploid Frog Xenopus laevis. Nature, 538, 336-343. https://doi.org/10.1038/nature19840

45. Hellsten, U., Simakov, O., Chapman, J., Fahey, B., Gauthier, M.E., Mitros, T., et al. (2010) The Genome of the Western Clawed Frog Xenopus tropicalis. Science, 328, 633-636. https://doi.org/10.1126/science.1183670

46. Pollet, N. and Mazabraud, A. (2006) Insights from Xenopus Genomes. Genome Dynamics, 2, 138-153. https://doi.org/10.1159/000095101

47. Tymowska, J. (1973) Karyotype Analysis of Xenopus tropicalis Gray, Pipidae. Cytogenetics and Cell Genetics, 12, 297-304. https://doi.org/10.1159/000130468

48. Sakaguchi, D.S., Murphey, R.K., Hunt, R.K. and Tompkins, R. (1984) The Development of Retinal Ganglion Cells in a Tetraploid Strain of Xenopus laevis. A Morphological Study Utilizing Intracellular Dye Injection. Journal of Comparative Neurology, 224, 231-251. https://doi.org/10.1002/cne.902240205

49. Ohno, S. (1970) Evolution by Gene Duplication. Springer, Berlin. https://doi.org/10.1007/978-3-642-86659-3

50. Janvier, P. (2010) Micro RNAs Revive Old Views about Jawless Vertebrate Divergence and Evolution. Proceedings of the National Academy of Sciences, 107, 19137-19138. https://doi.org/10.1073/pnas.1014583107

51. Van Rheede, T., Bastiaans, T., Boone, D.N., Hedges, S.B., de Jong, W.W. and Madsen, O. (2006) The Platypus Is in Its Place: Nuclear Genes and Indels Confirm the Sister Group Relation of Monotremes and Therians. Molecular Biology and Evolution, 23, 587-597. https://doi.org/10.1093/molbev/msj064 


\section{EXTENDED DATA TEXT: APPLICATION OF NEWLY DEVELOPED ANALYTICAL METHOD TO VARIOUS ORGANISMS' MITOCHONDRIAL GENOMES}

No positive nucleotide content differences were observed in rat (Rattus norvegicus) or mouse (Mus musculus castaneus) mtDNA. The mitochondria of rodents, hedgehog (Erinaceus europaeus), guinea pig (Cavia porcellus), and hamster (Mesocricetus auratus) showed quite similar nucleotide content difference patterns, except for the presence of AT inversion in the second fragment (Extended Data Figure 2(a)). The Laotian rock rat, Laonastes aenigmamus, was described as a new family in 2005 [38], but the classification was changed to Diatomyidae in 2006 [39]. The mtDNA nucleotide content pattern of this rat completely differed from those of the other rodents examined in this study, although it resembled that of the Asian pangolin (Manis pentadactyla) (Extended Data Figure 2(a)). Pangolins are classified into two groups, African (Manis tetradactyla) and Asian, based on morphological characteristics [40]. In African pangolins, AT content inversion was observed in the second mtDNA fragment, while positive $(\mathrm{T}-\mathrm{C})$ differences were observed in all three mtDNA fragments of Asian pangolins. The African pangolin pattern resembled that of prosimian L. catta, while the Asian pangolin pattern resembled that of reptile Heteronotiabinoei (Bynoe's gecko). Although they belong to the same genus, the two pangolins are remarkably separated in terms of genome biological divergence.

The ocean-dwelling mammal platypus, Ornithorhynchus anatinus, and the short-beaked echidna, Tachyglossus aculeatus, both belong to the order Monotremata, and seem to be the most primitive mammals. TA inversion occurred in the second mtDNA fragment of both these animals (Extended Data Figure 2(b)). Recently, it was reported that whales are related to hippopotamus [41, 42]. Upon examination in the current study, consistent results were obtained based on Ward's clustering analyses using amino acid compositions or nucleotide contents predicted from complete mitochondrial genomes as traits [43], or using 16S rRNA sequences [43]. However, nucleotide content difference patterns of mtDNA from whale (Balaenoptera musculus) and dolphin (Phocoena phocoena) species did not resemble that of the pygmy hippopotamus (Hexaprotodon liberiensis) or rhinoceros (Diceros bicornis) (Extended Data Figure 2(b)). In fact, the whale and dolphin patterns resembled those of primate species $N$. coucang and $T$. belangeri. This discrepancy should be clarified in the future. Nucleotide content difference patterns of mtDNA from birds (G. gallus and T. guttata) resembled that of primates (Figure 4 and Extended Data Figure 2(b)). This suggests that birds and primates have a similar level of divergence, as described previously [11]. However, a significant difference was observed between the two groups: the $(\mathrm{C}-\mathrm{T})$ difference in the second fragment was smaller than that of the first and third fragments in the mtDNA of birds.

Amphibians are classified into the tailed Caudata (Lyciasalamandra atifi and Cynops pyrrhogaster) and the non-tailed Anua (Xenopus laevis, Rana nigromaculata, and Bufo japonicus) groups. This classification was also confirmed by nucleotide content difference patterns (Extended Data Figure 2(c)). AT, $\mathrm{CT}$, and AC inversions were observed in the latter group, while only AT inversion was observed in the former, except for $X$. laevis. In $X$. laevis and Dermophis mexicanus (limbless amphibian) mtDNA, there is no nucleotide content inversion. In contrast, $X$. tropicalis mitochondria have both CT and CA inversion. Xenopus species, $X$. laevis [44] and $X$. tropicalis [45], whose complete genome sequences were analysed, are exciting models for the study of gene duplication that can result from hybridization among species [46]. Their mitochondrial nucleotide content difference patterns are quite different from each other. Eventually, the G and C values for $X$. tropicalis (G: 0.144, C: 0.281) mtDNA, which is diploid [47], were higher than those of $X$. laevis (G: 0.135, C: 0.235), which is a pseudo-tetraploid [48]. This fact clearly indicates that the highly evolved $X$. tropicalis diverged via a hybridized ancestor, such as $X$. laevis. Thus, $X$. laevis and $X$. tropicalis seem to be an excellent model to understand evolution based on gene duplication [49].

In aquatic vertebrates, the nucleotide content difference pattern of hagfish, Eptatretus burgeri, which has been proposed as an ancestor of vertebrates [50], resembled that of lamprey, Lampetra fluviatilis (Extended Data Figure 2(e)). Among the Gnathostomata, the mtDNA nucleotide content difference pattern of sea horse (Hippocampus kuda) differed from that of seaweed pipefish (Syngnathus schlegeli), al- 
though they both belong to the class Actinopterygii. The sea horse pattern resembled that of the Chondrichthyes species thorny skate (Amblyraja radiata) and brownbanded bambooshark (Chiloscyllium punctatum), amphibians (L. atifi and $C$. pyrrhogaster), and platypus ( $O$. anatinus), which is an ancestor of mammals [51]. The mtDNA nucleotide content difference pattern of the coelacanth Latimeria chalumnae resembled that of eel (Anguilla marmonata) and lung fish (Neoceratodus forsteri), all of which were similar to the mtDNA of reptiles (Extended Data Figure 2(d)). These organisms are characterized by AT inversion in the second fragment. These similarities seem to reflect evolutionary processes from aquatic to terrestrial animals [11].

In non-animals, the mtDNA of fungal species Smittium culisetae showed the lowest GC and C contents, while the highest values were observed in Cycas species Cycas taitungensis mtDNA (Figure 1). GC inversion was observed in the former while both GC and AT inversions were observed in the latter (Extended Data Figure 3). In chloroplasts, no nucleotide inversion was observed in the red alga Cyanidioschyzon merolae, whose GC content was the lowest, while both GC and AT inversions were observed in the green alga Chara vulgaris, which had the highest GC content. Regarding C content, however, the $C$. vulgaris chloroplast $\mathrm{C}$ content was the lowest amongst the samples examined, while the mtDNA of the green alga Nephroselmi solivacea showed the highest C content, and was accompanied by GC and AT inversions.

GC and AT inversions in nucleotide content differences were observed in U. urealyticum, Mycoplasma pulmonis, Rickettsia prowazekii, Staphylococcus aureus, and Escherichia coli, while minor GC inversion was observed in $S$. coelicolor, which had the highest GC content of all organisms examined (Extended Data Figure 4). Amongst the archaea, both GC and AT inversions were observed in Pyrococcushorikoshii, while only GC inversion was observed in Halobacterium. The inversion patterns based on $(\mathrm{G}-\mathrm{T}),(\mathrm{G}-\mathrm{A}),(\mathrm{C}-\mathrm{T})$ and $(\mathrm{C}-\mathrm{A})$ occurred between low $\mathrm{GC}$ content bacteria such as Ureaplasma urealyticum (G: 0.131, C:0.127), Mycoplasma pulmonis (G: 0.133, C: 0.133), Rickettsia prowazekii (G: 0.146, C: 0.144), Staphylococcus aureus (G: 0.167, C: 0.165) and Pyrococcus horikoshii (G: 0.207, C: 0.212), and high GC content bacteria such as Halobacterium (G: 0.339, C: 0.340)and Streptomyces coelicor (G: 0.361, C: 0.359 ). Escherichia coli (G: 0.254, C: 0.254) showed the intermediate pattern.

The microsporidian protozoan Encephalitozoon cuniculi is a special eukaryote that lacks mitochondria, although it contains 11 chromosomes. Interestingly, the nucleotide contents of the chromosomes were almost identical (Extended Data Figure 5). GC and AT inversions, as well as other nucleotide content inversions, were observed among the 11 chromosomes of E. cuniculi, and nucleotide content difference patterns differed among the chromosomes (Extended Data Figure 5). 


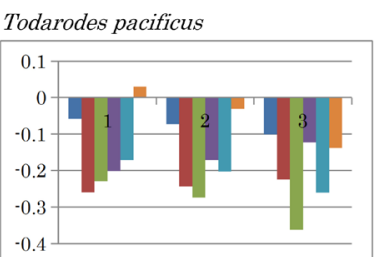

Octopus vulgaris

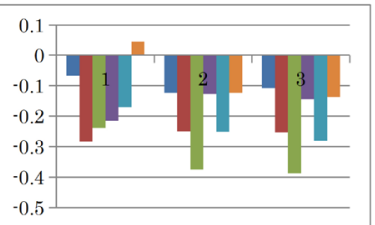

Paracentrotus lividus

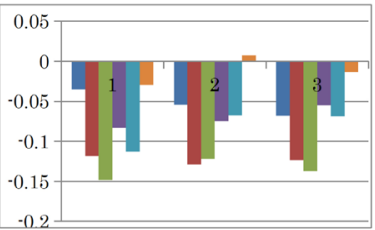

Daphnia pulex

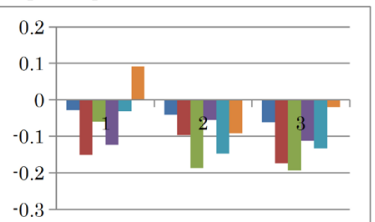

(a)

Schistosoma mansoni

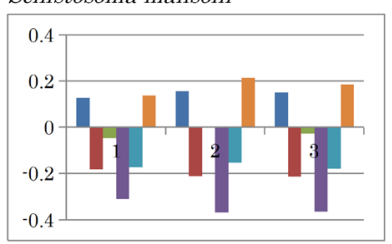

Geodia neptuni

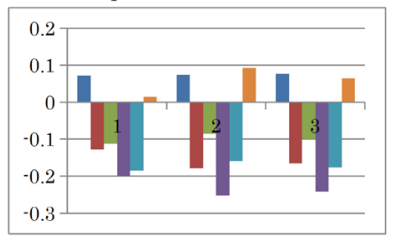

Tigriopus californicus

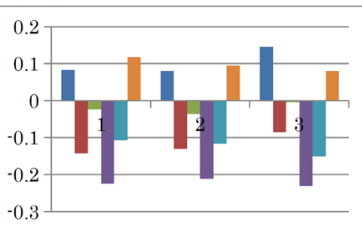

Branchiostoma belcheri

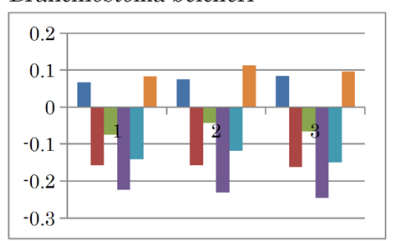

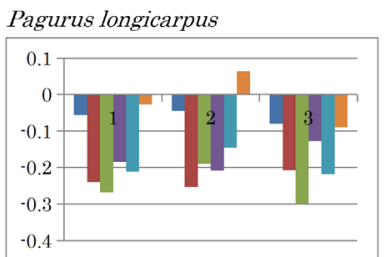

Dosidicus gigas

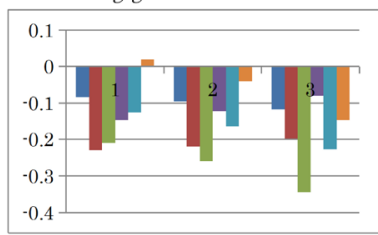

Paragonimus westermani

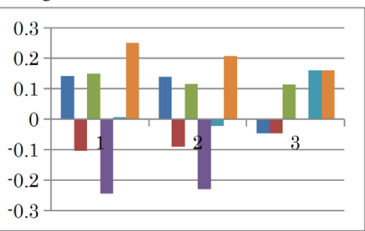

Pavona clavus
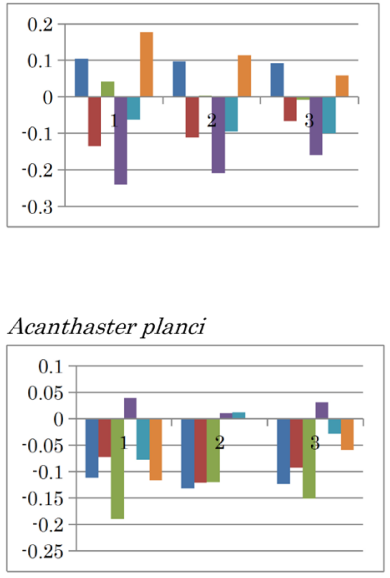

Haliotis rubra

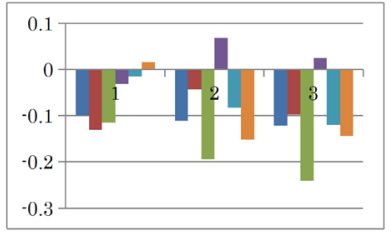

Lampsilis ornata

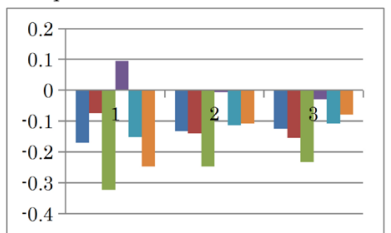

(b) 

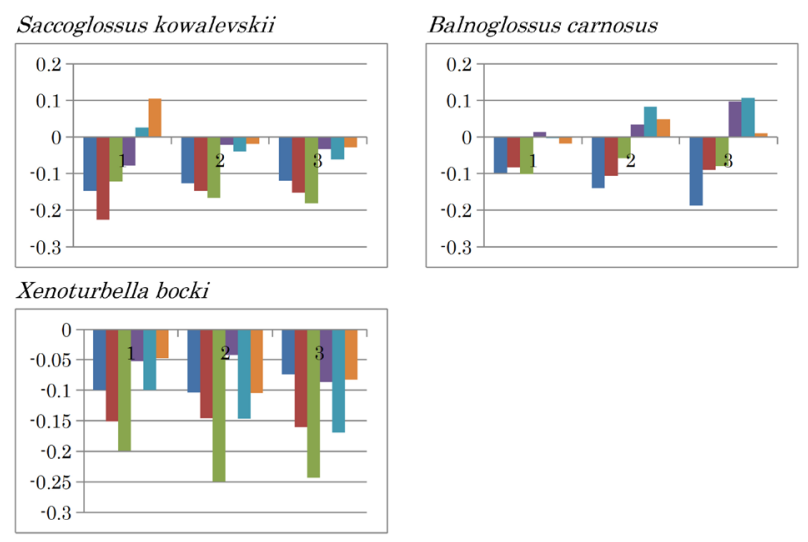

(c)

Extended Data Figure 1. Nucleotide content differences in the three fragments of the mitochondrial genomes of invertebrates. 1,2 , and 3 represent the sequentially divided first, second, and third fragments, respectively. Left to right: $(G-C),(G-T),(G$ - A), (C - T), (C -A), and (T - A). 

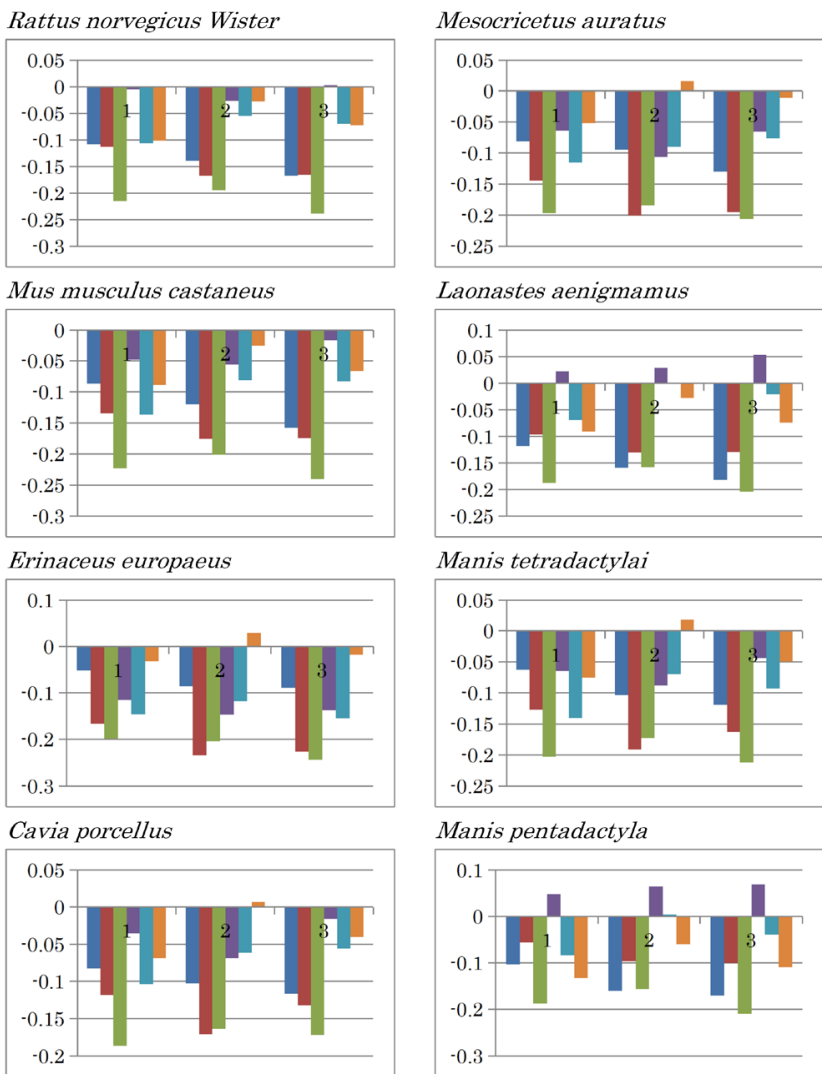

Manis pentadactyla

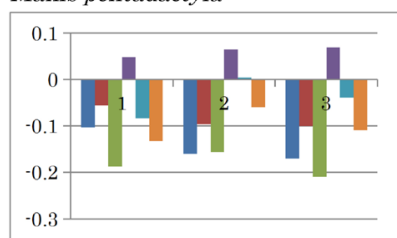

(a)
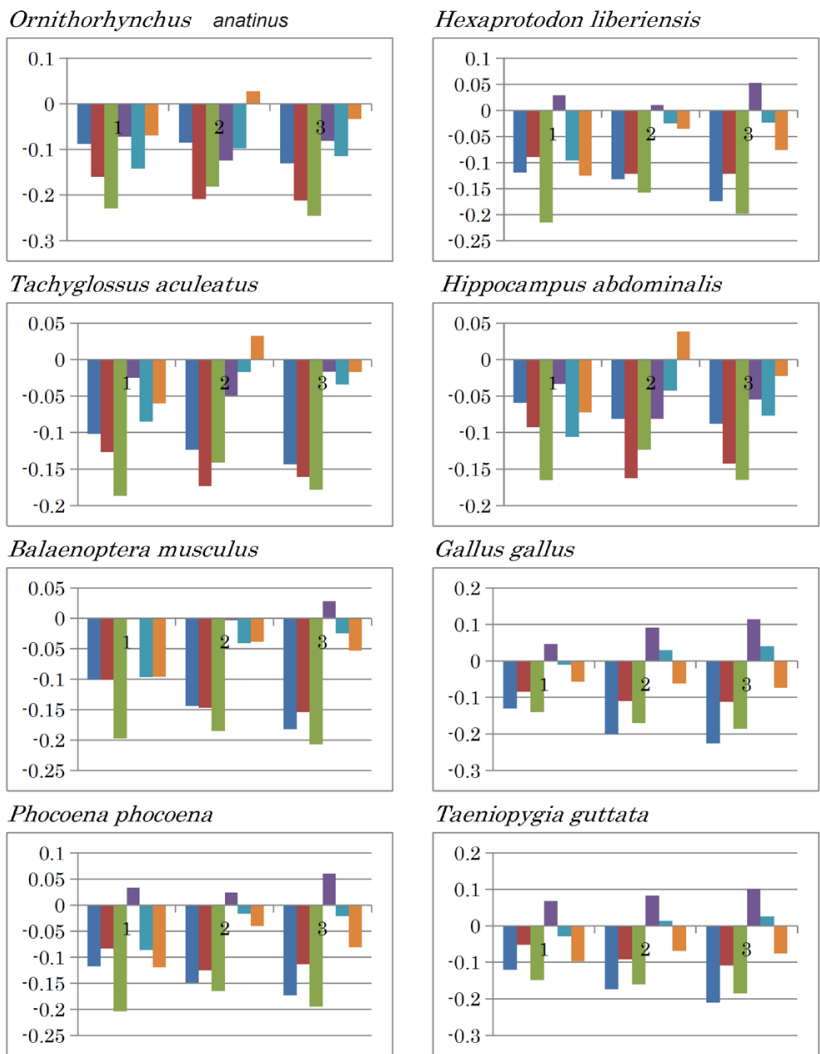

Hippocampus abdominalis

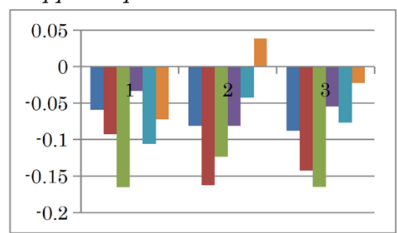

Gallus gallus

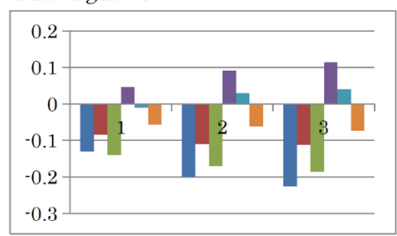

Taeniopygia guttata

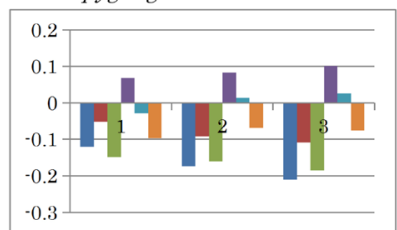

(b) 

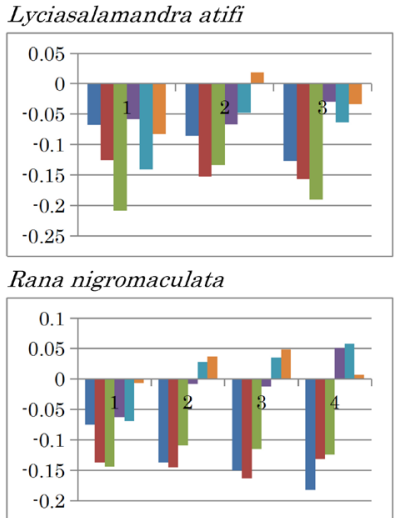

Xenopus laevis

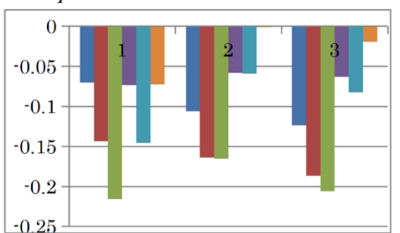

Dermophis mexicanus

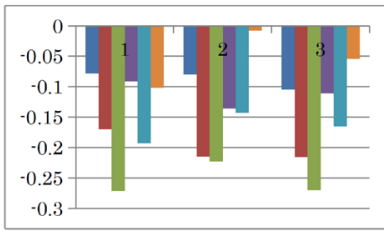

(c)

Chlamydosaurus kingii

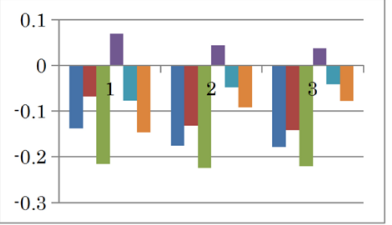

Gekko gecko

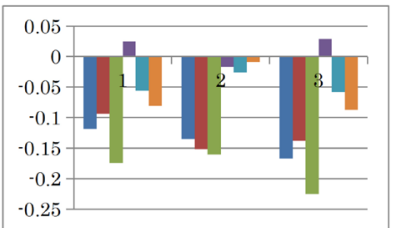

Heteronotia binoei

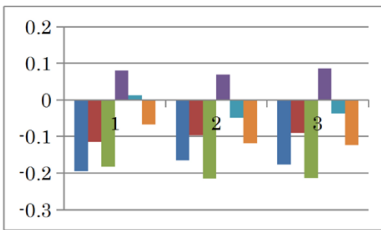

Alligator mississippiensis

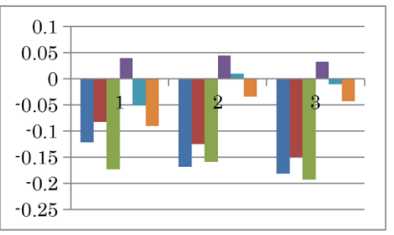

Cynops pyrrhogaster

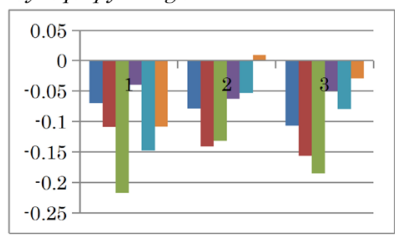

Bufo japonicus

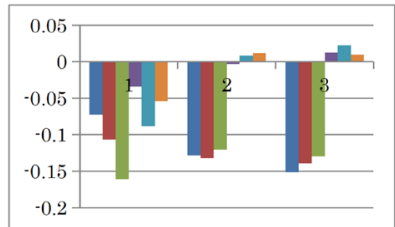

Xenopus (Silurana) tropicalis

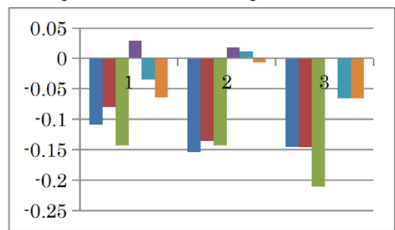

Crocodylus niloticus

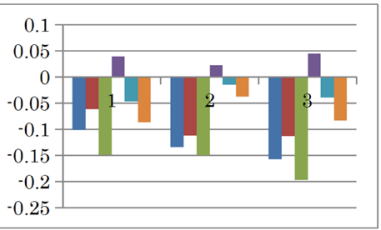

Gavialis gangeticus

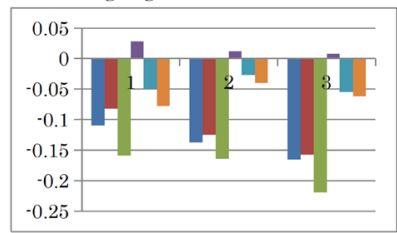

Boa constrictor

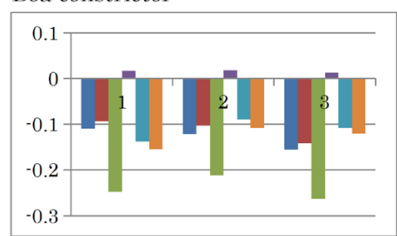

Chelonia mydas

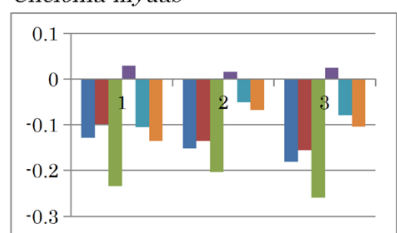

(d) 

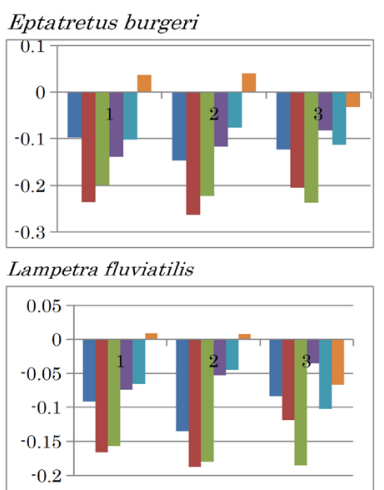

Hippocampus kuda

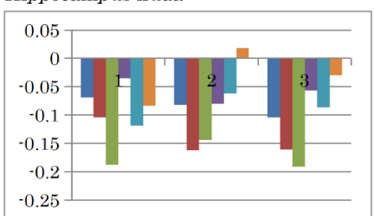

Syngnathus schlegeli

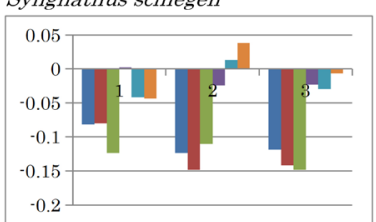

(e)
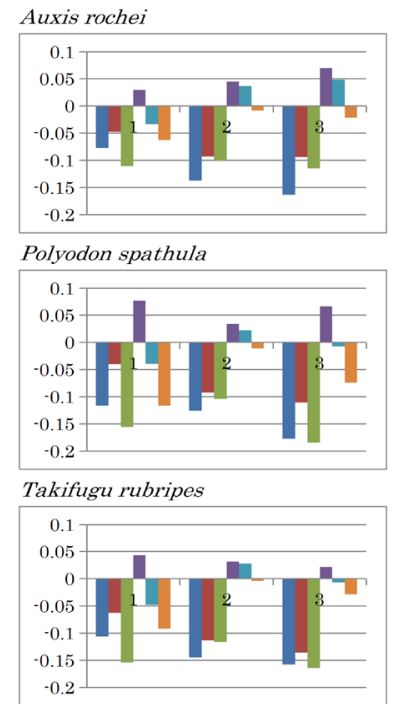

Oncorhynchus mykiss

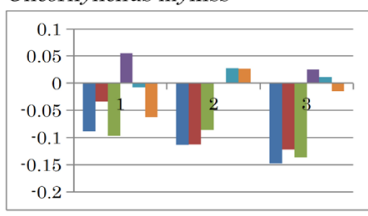

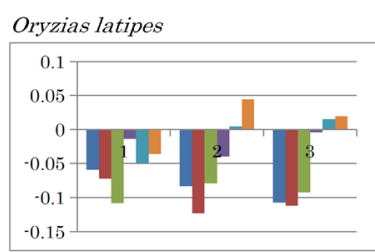

Anguilla marmorat

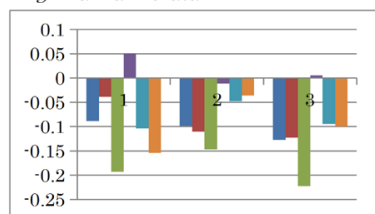

Latimeria chalumnae

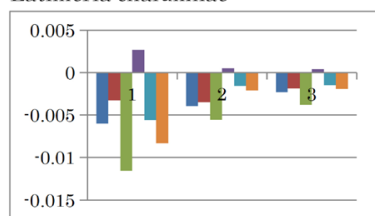

Neoceratodus forsteri

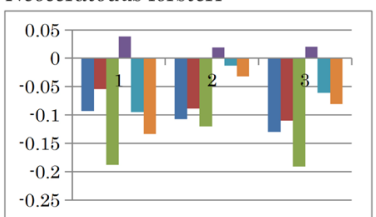

e)

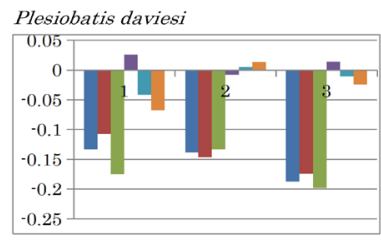

Heterodontus francisci

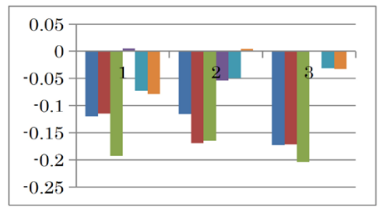

Chiloscyllium punctatum

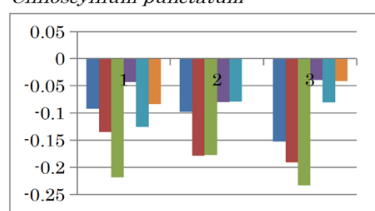

Amblyraja radiata

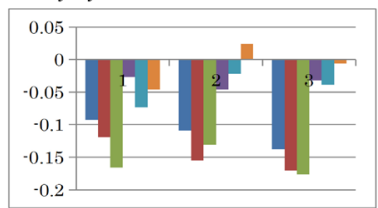

(f)

Extended Data Figure 2. Nucleotide content differences in the three fragments of the mitochondrial genomes of vertebrates. 1,2 , and 3 represent the sequentially divided first, second, and third fragments, respectively. Left to right: $(G-C),(G-T),(G-A),(C-T),(C-A)$, and $(T-A)$. 


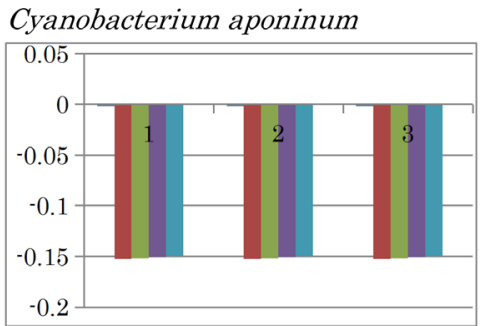

Smittium culisetae $\mathrm{Mt}$

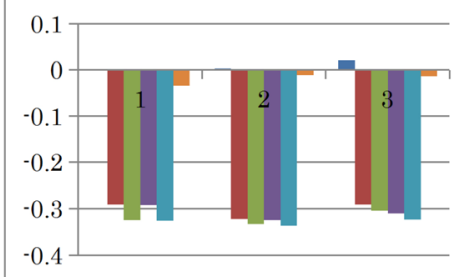

Cyanidioschyzon merolae chloplast

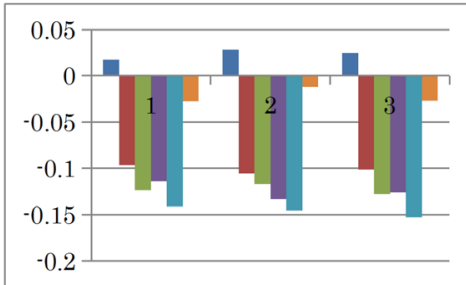

Cycas titungensis $\mathrm{Mt}$

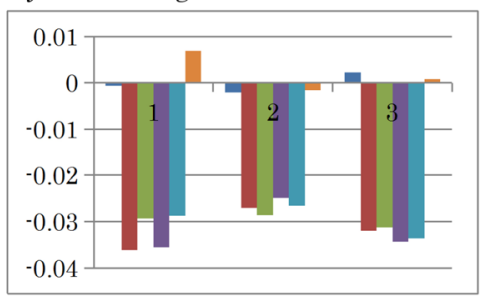

Chara vulgaris chloroplast

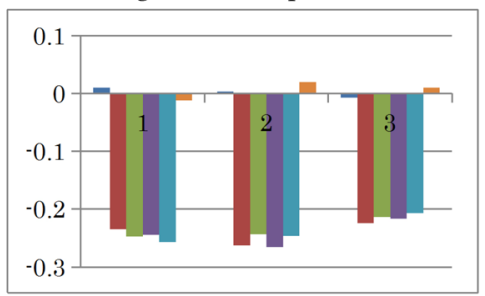

Nephroselmis olivacea chloroplast

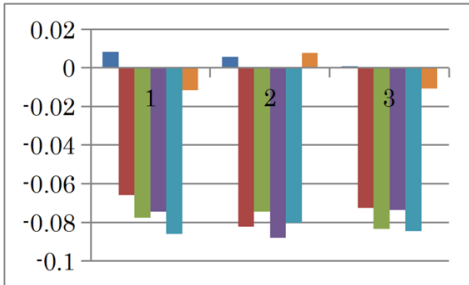

Extended Data Figure 3. Nucleotide content differences in the three fragments of the mitochondrial genomes of non-animal mitochondria and chloroplasts. 1, 2, and 3 represent the sequentially divided first, second, and third fragments, respectively. Left to right: $(G-C),(G-T),(G-$ $A),(C-T),(C-A)$, and $(T-A)$. 
Ureaplasma urealyticum

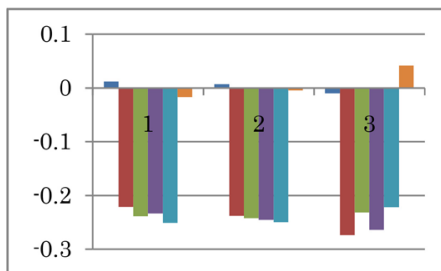

Rickettsia prowazekii

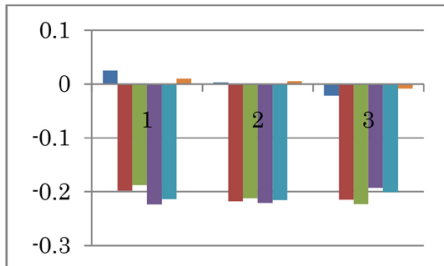

Stapylococcus aureus

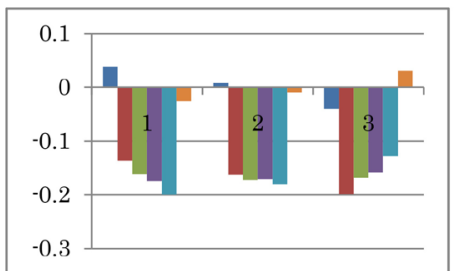

Pyrococcus horikoshii

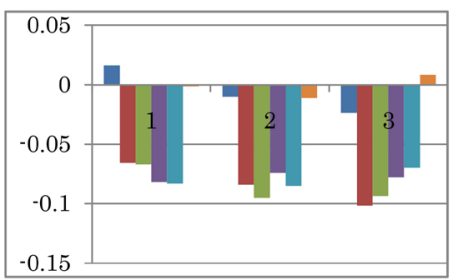

Mycoplasma pulmonis

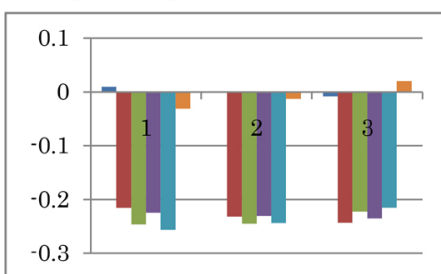

Streptomyces coelicolor

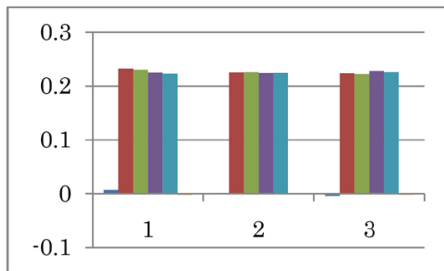

Escherichia coli K12

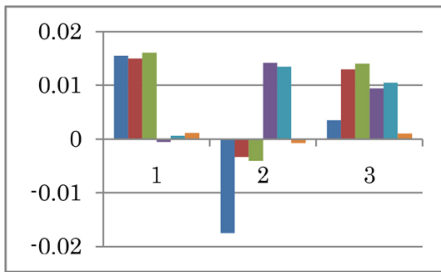

Halobacterium sp.NRC-1

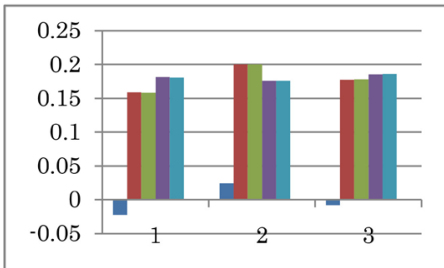

Extended Data Figure 4. Nucleotide content differences in the three fragments of bacterial genomes. 1, 2, and 3 represent the sequentially divided first, second, and third fragments, respectively. Left to right: $(G-C),(G-T),(G-A),(C-T),(C$ $-A)$, and ( $T-A)$. 

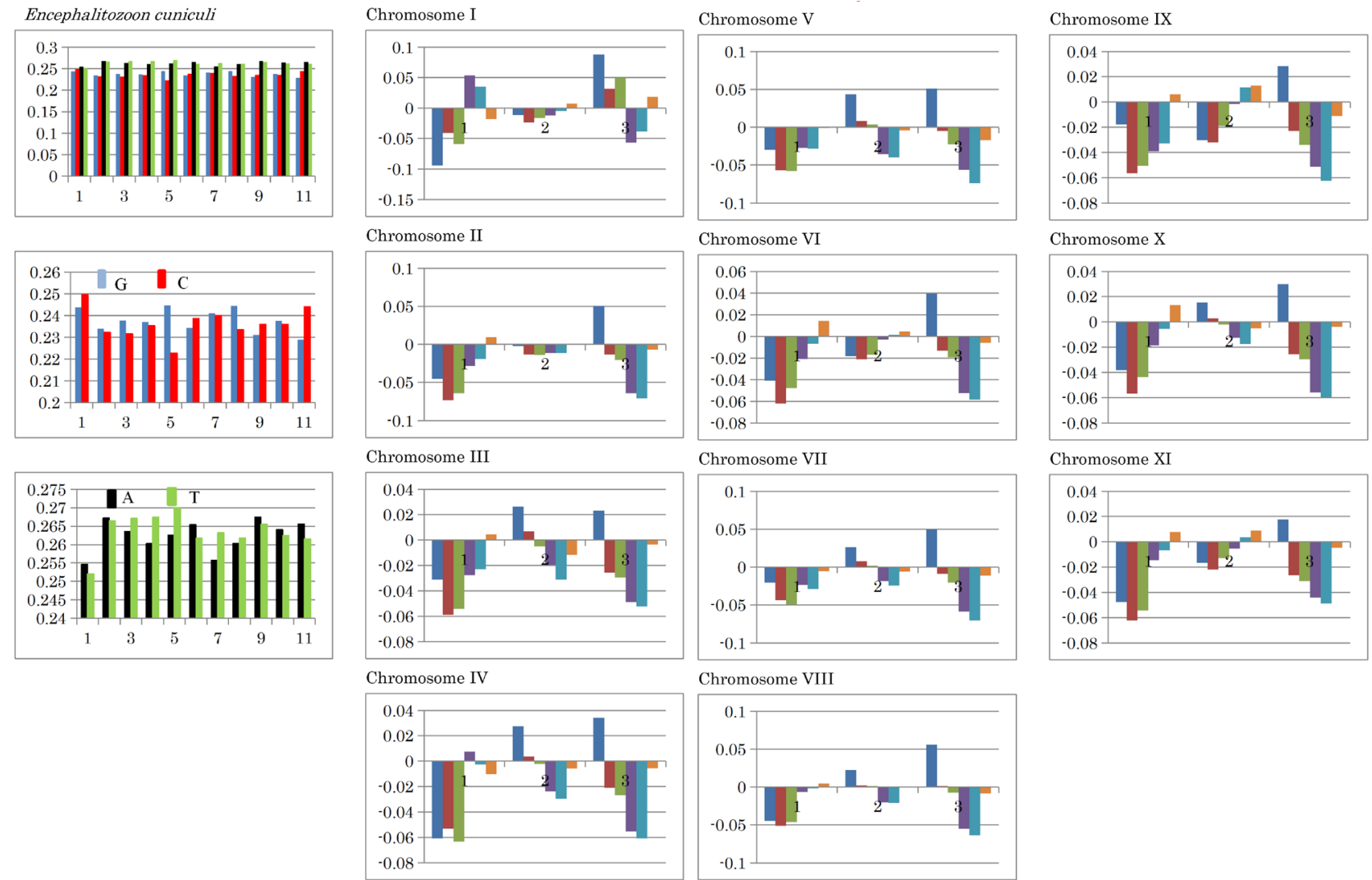

Extended Data Figure 5. Nucleotide content differences in the three fragments of the chromosome of microsporidian protozoan species Encephalitozoo ncuniculi. Left to right: (G-C), (G-T), (G-A), $(C-T),(C-A)$, and $(T-A)$.

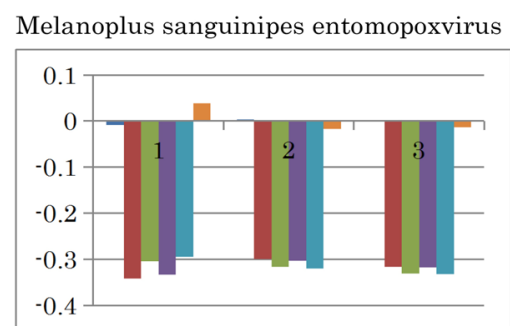

Mollivirus sibericum

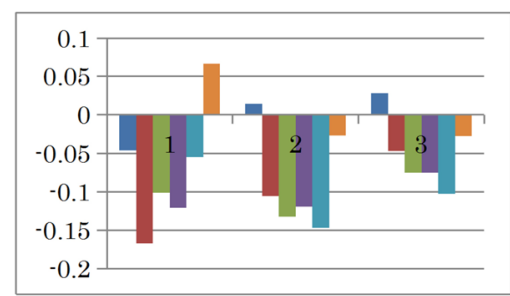

Papio ursinus cytomegalovirus

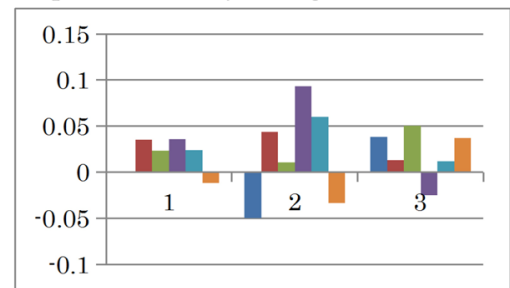

DeBrazza's monkey virus 1

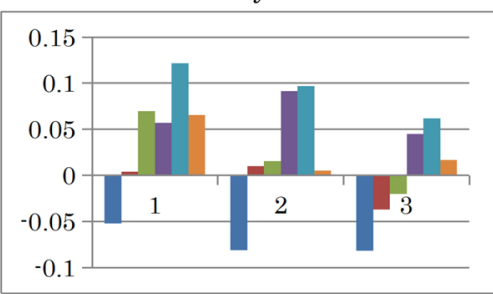

Extended Data Figure 6. Nucleotide content differences in the three fragments of viral genomes. 1, 2, and 3 represent the sequentially divided first, second, and third fragments, respectively. Left to right: $(G-C),(G-T),(G-A),(C-T),(C-A)$, and $(T-A)$. 


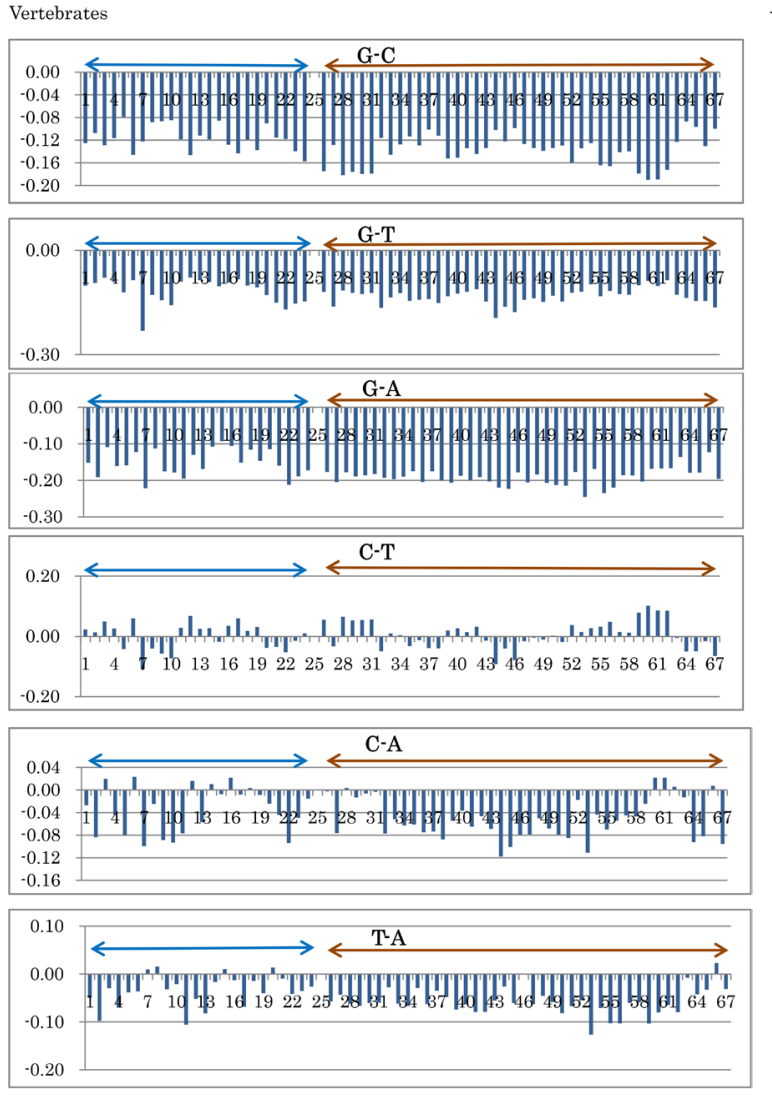

(a)

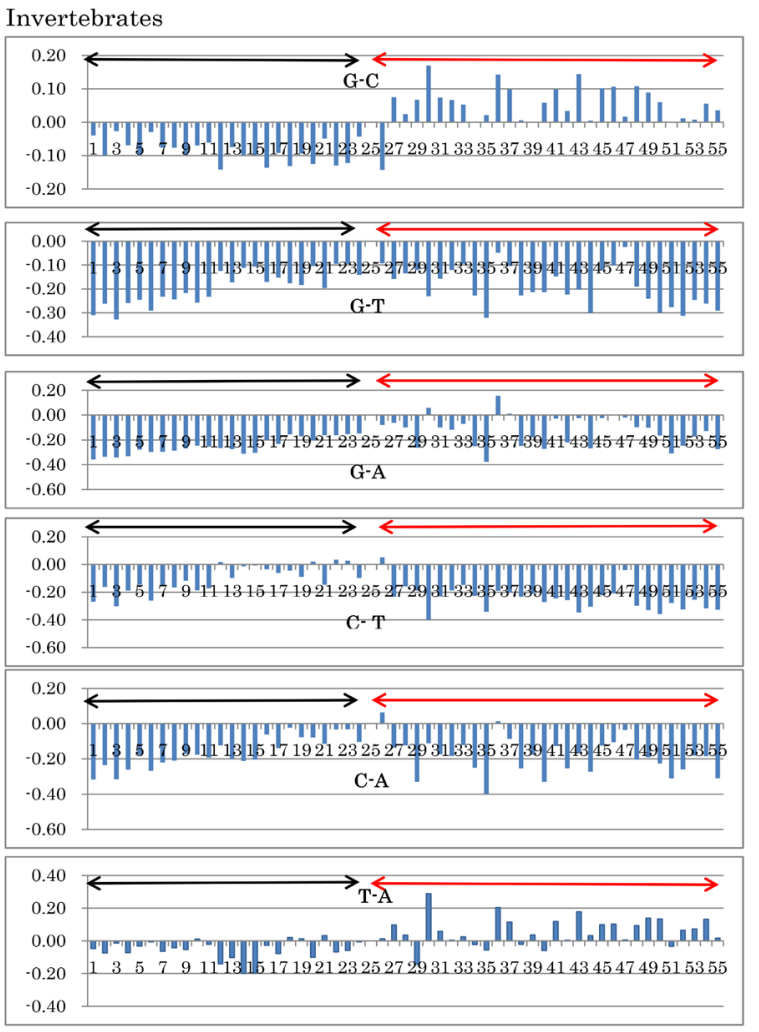

$\begin{array}{cl}\text { Vertebrate mitochondria } \\ \text { No. } & \text { Organism } \\ 1 & \text { Amia calva } \\ 2 & \text { Anguilla marmorata } \\ 3 & \text { Auxis rochei } \\ 4 & \text { Cyprinus carpio } \\ 5 & \text { Danio rerio } \\ 6 & \text { Diodon holocanthus } \\ 7 & \text { Eptatretus burgeri } \\ 8 & \text { Gadus morhua } \\ 9 & \text { Hippocampus kuda } \\ 10 & \text { Lampetra fluviatilis } \\ 11 & \text { Latimeria chalumnae } \\ 12 & \text { Myripristis berndti } \\ 13 & \text { Neoceratodus forsteri } \\ 14 & \text { Oncorhynchus mykiss } \\ 15 & \text { Oryzias latipes } \\ 16 & \text { Paralichthys olivaceus } \\ 17 & \text { Polyodon spathula } \\ 18 & \text { Reinhardtius hippoglossoides } \\ 19 & \text { Takifugu rubripes } \\ 20 & \text { Theragra chalcogramma } \\ 21 & \text { Amblyraja radiata } \\ 22 & \text { Chiloscyllium punctatum } \\ 23 & \text { Heterodontus francisci } \\ 24 & \text { Plesiobatis daviesi } \\ 25 & \\ 26 & \text { Gorilla gorilla } \\ 27 & \text { Lemur catta } \\ 28 & \text { Homo sapiens } \\ 29 & \text { Macaca mulatta } \\ 30 & \text { Pan paniscus } \\ 31 & \text { Pan troglodytes } \\ 32 & \text { Artibeus jamaicensis } \\ 33 & \text { Balaenoptera musculus } \\ & \end{array}$

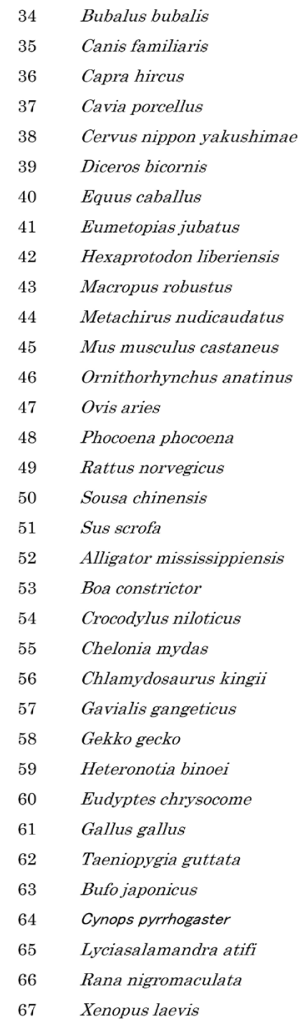


Non-animal Mt

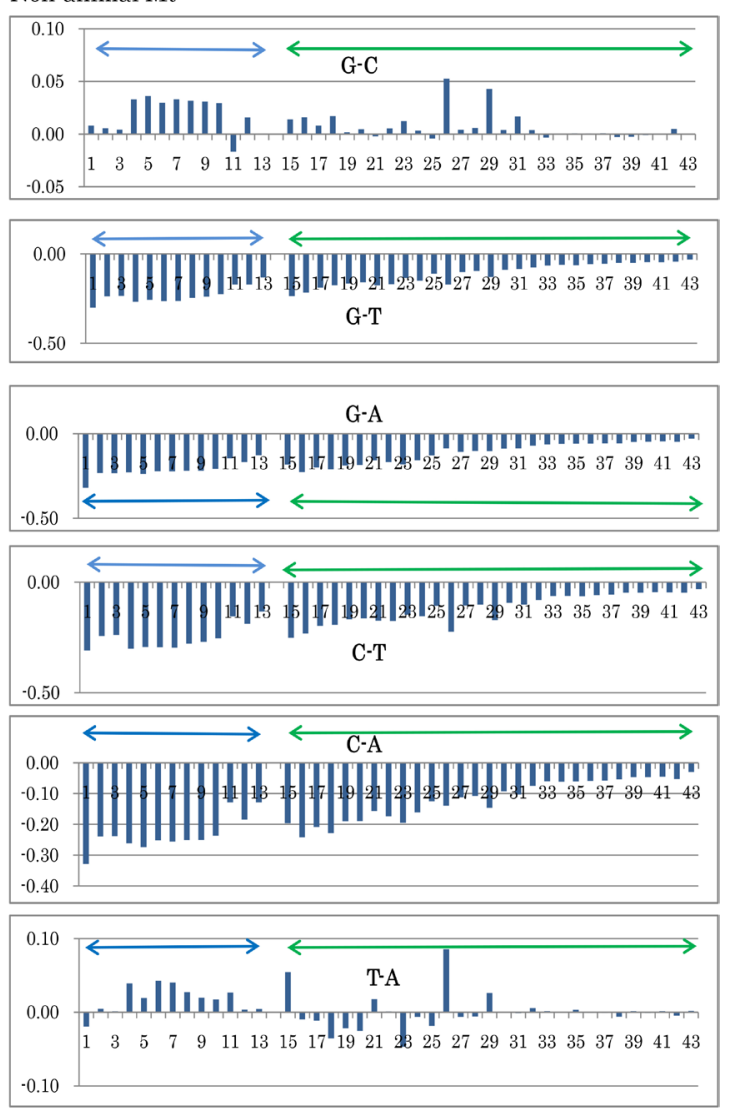

Non-animal mitochondria

\begin{tabular}{|c|c|c|c|}
\hline No. & Organism & 23 & Porphyra purpurea \\
\hline 1 & Smittium culisetae & 24 & Chaetosphaeridium \\
\hline 2 & Rhizopus oryzae & & globosum \\
\hline 3 & Pleurotus ostreatus & 25 & Ostreococcus tauri \\
\hline 4 & Trichophyton rubrum & 26 & Fucus vesiculosus \\
\hline 5 & Epidermophyton floccosum & 27 & Pseudendoclonium \\
\hline 6 & Microsporum canis & & akinetum \\
\hline \multirow[t]{2}{*}{7} & Trichophyton & 28 & Chlorokybus atmophyticus \\
\hline & mentagrophytes & 29 & Scenedesmus obliquus \\
\hline 8 & Sporothrix schenckii & 30 & Chara vulgaris \\
\hline 9 & Aspergillus fumigatus & 31 & Physcomitrella patens \\
\hline 10 & Aspergillus niger & 32 & Marchantia polymorpha \\
\hline 11 & Cryptococcus neoformans & 33 & Sorghum bicolor \\
\hline 12 & Candida albicans & 34 & Zea mays \\
\hline 13 & Candida tropicalis & 35 & Oryza sativa \\
\hline 14 & & 36 & Vitis vinifera \\
\hline 15 & Emiliania huxleyi & 37 & Triticum aestivum \\
\hline 16 & Cyanidioschyzon merolae & 38 & Arabidopsis thaliana \\
\hline 17 & Thalassiosira pseudonana & 39 & Brassica napus \\
\hline 18 & Rhodomonas salina & 40 & Lotus japonicus \\
\hline 19 & Mesostigma viride & 41 & Daucus carota \\
\hline 20 & Phaeodactylum & 42 & Chlamydomonas \\
\hline & tricornutum & & reinhardtii \\
\hline 21 & Oltmannsiellopsis viridis & 43 & Cycas taitungensis \\
\hline
\end{tabular}

22 Nephroselmis olivacea

(c)

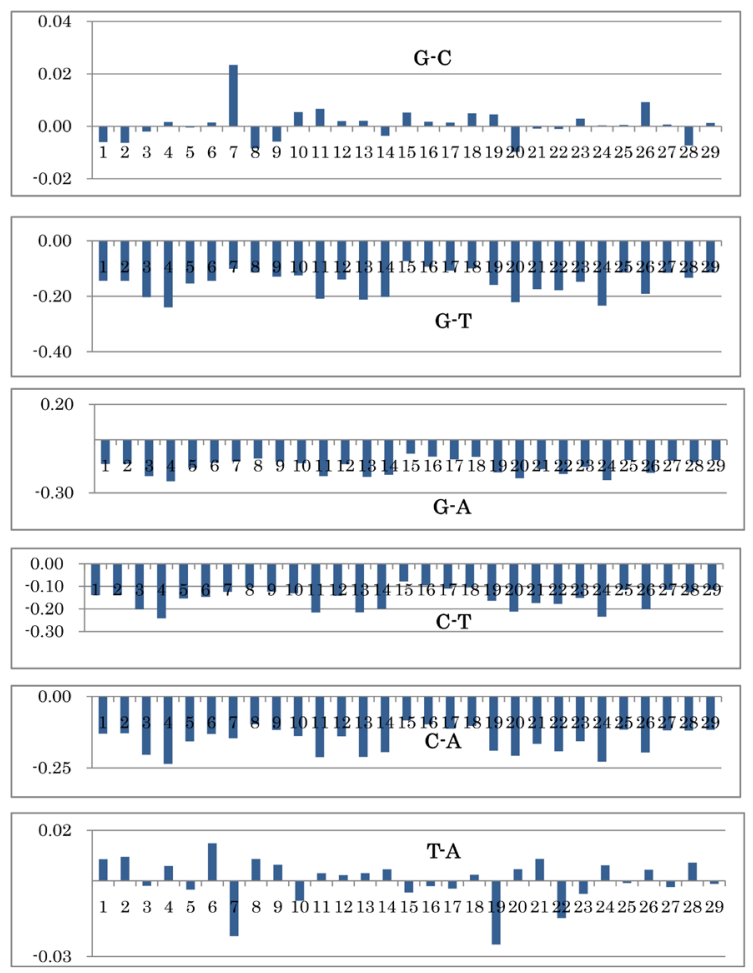

$\begin{aligned} \text { No. } & \text { Organism } \\ 1 & \text { Arabidopsis thaliana } \\ 2 & \text { Brassica napus } \\ 3 & \text { Chaetosphaeridium } \\ & \text { globosum } \\ 4 & \text { Chara vulgaris } \\ 5 & \text { Chlamydomonas } \\ & \text { reinhardtii } \\ 6 & \text { Chlorokybus } \\ & \text { atmophyticus } \\ 7 & \text { Cyanidioschyzon merolae } \\ 8 & \text { Cycas taitungensis } \\ 9 & \text { Daucus carota } \\ 10 & \text { Emiliania huxleyi } \\ 11 & \text { Fucus vesiculosus } \\ 12 & \text { Lotus japonicus } \\ 13 & \text { Marchantia polymorpha } \\ 14 & \text { Mesostigma viride }\end{aligned}$

\section{Chloroplasts}

Nephroselmis olivacea Oltmannsiellopsis viridis Oryza sativa

Ostreococcus tauri

Phaeodactylum tricornutum Physcomitrella patens Porphyra purpurea Pseudendoclonium akinetum Rhodomonas salina Scenedesmus obliquus Sorghum bicolor Thalassiosira pseudonana Triticum aestivum Vitis vinifera Zea mays 

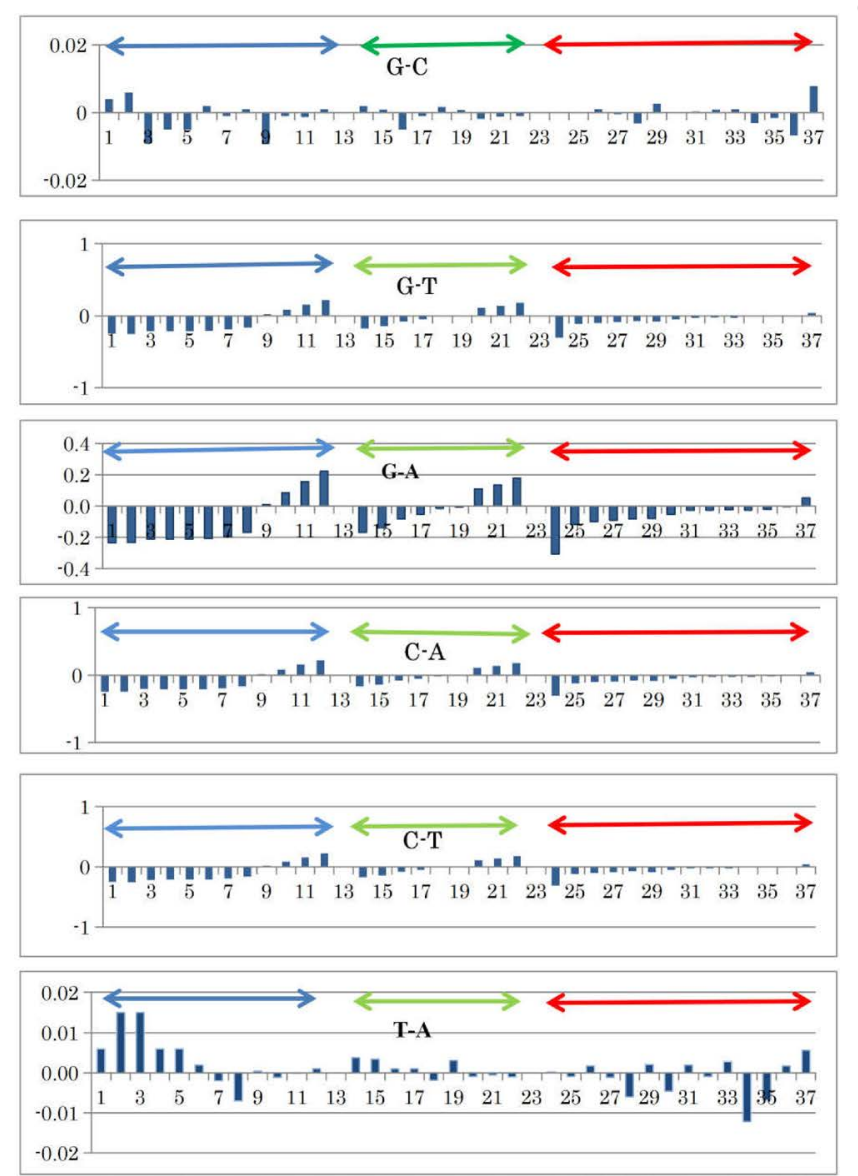

Chlomosomes

No. Organism

Ureaplasma urealyticum

Mycoplasma pulmonis

Clostridium perfringens $1^{-}$

10

Rikettsia prowazekii

Clostridium tetani

Rickettsia prowazekii

Campylobacter jejuni

Staphylococcus aureus

Escherichia coli $\mathrm{K} 12$

Agrobacterium tumefaciens

Mycobacterium

tuberculosis $H 37 R$ V

Streptomyces coelicolor

Sulfolobus tokodaii

Sulfolobus solfataricus P2

Pyrococcus horikoshii

Pyrococcus abyssi

Archaeoglobus fulgidus

DSM 4304

Methanothermobacter

Methanopyru kandleri

AV19

Methylococcus capsulatus

str Bath

Halobacterium

Plasmodium falciparum

Saacharomyces cerevisiae

Taeniopygia guttata

Canis lupus familiaris

Gorilla gorilla
Ornithorhynchus anatinus

Equus caballus

Ovis aries

Encephalitozoon cuniculi

Bos taurus

Homo sapiens

Mus musculus

Rattus norvegicus

Gallus gallus

(e)

Extended Data Figure 7. Nucleotide differences. (a) Mitochondria of aquatic vertebrates (blue arrow) and terrestrial vertebrates (red arrow). (b) Mitochondria of high C/G invertebrates (black arrow) and low C/G invertebrates (red arrow). (c) Non-animal mitochondria of fungi (blue arrow) and plants (green arrow). (d) Chloroplasts. (e) Chromosomes of prokaryotes (blue arrow), archaea (green arrow), and eukaryotes (red arrow). 

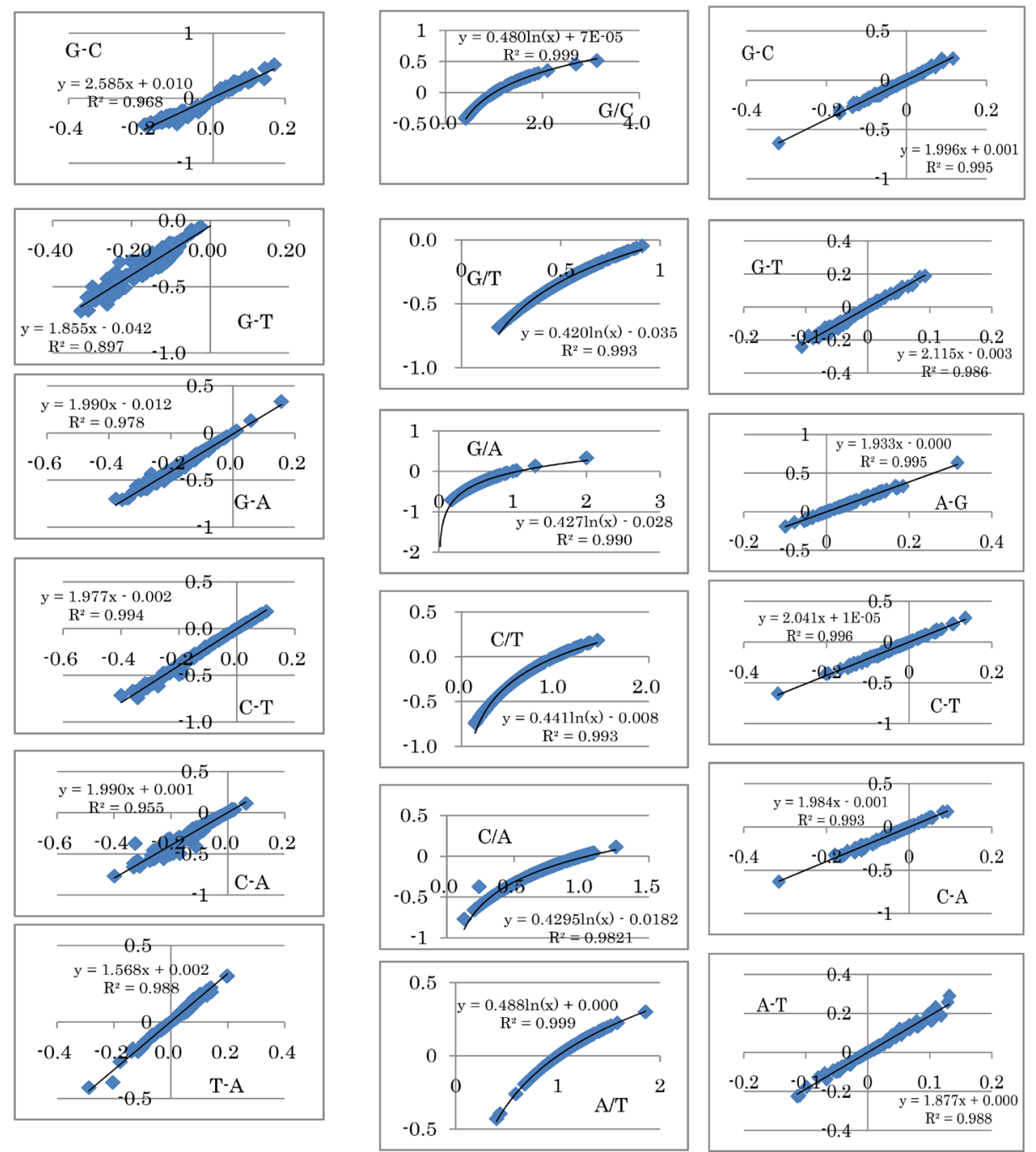

(a)

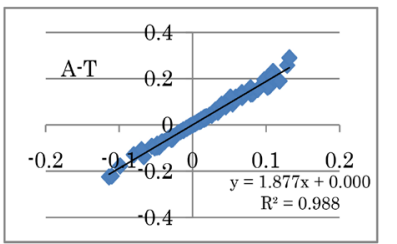

(b)
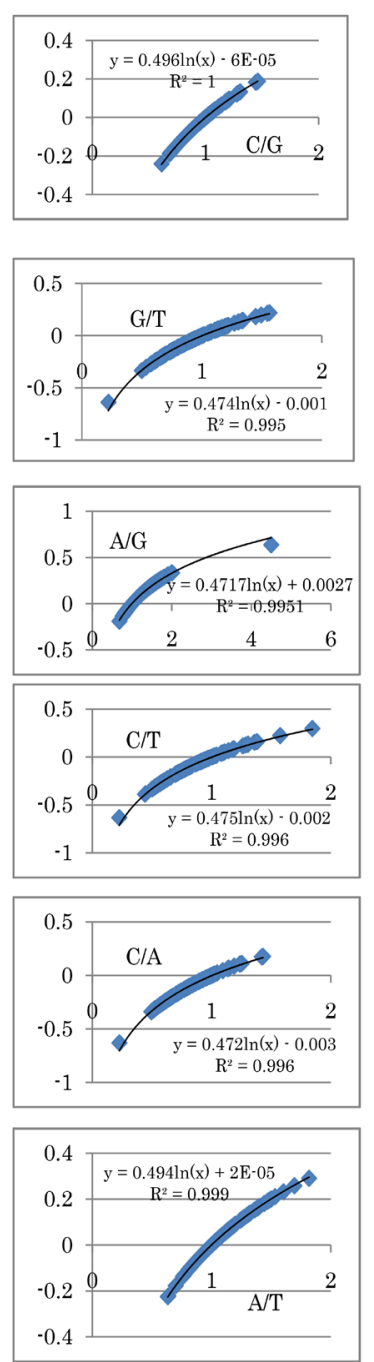

(b)

Extended Data Figure 8. Universal rules. Left side: relationship between $(\mathrm{X}-\mathrm{Y})$ and $(\mathrm{X}-\mathrm{Y}) /(\mathrm{X}+\mathrm{Y})$, and right side: relationship between $(\mathrm{X} / \mathrm{Y})$ and $(\mathrm{X}-\mathrm{Y}) /(\mathrm{X}+\mathrm{Y}) .(\mathrm{a})$ : organelles and $(\mathrm{b})$ : viruses. 
Extended Data Table 1. List of viruses used.

\begin{tabular}{|c|c|c|c|}
\hline & Viruses & NC_No. & \\
\hline 1 & Gemycircularvirus & NC_027821 & sDNA, linear. \\
\hline 2 & Pan troglodytes polyomavirus 1 & NC_027532 & DNA, circular. \\
\hline 3 & Mollivirus sibericum isolated P1084-T & NC_027867 & DNA, linear. \\
\hline 4 & Ruttus norvegicus polyomervirus & NC_027531 & DNA, circular \\
\hline 5 & Alfalfa leaf curl virus & NC_027714 & DNA, circular \\
\hline 6 & Poaceae-associated gemycircular virus & NC_027820 & DNA, circular \\
\hline 7 & New Jersey polyomer-2013 virus & NC_024118 & DNA, circular \\
\hline 8 & Vaccinia virus & NC_006998 & DNA, linear. \\
\hline 9 & Taro bacilliform virus & NC_026819 & DNA, circular \\
\hline 10 & Salmon gill povirus & NC_027707 & DNA, linear. \\
\hline 11 & Skunk adenovirus PBI virus & NC_027708 & DNA, linear. \\
\hline 12 & Spodotera exigua nucleopolyhedrovirus & NC_002169 & DNA, circular \\
\hline 13 & Temperate fruit decay-associated virus & NC_027632 & DNA, circular \\
\hline 14 & Rubus yellow net virus & NC_026238 & DNA, linear. \\
\hline 15 & Agrotis segetum nucleopolyhedrovirus & NC_025960 & DNA, circular \\
\hline 16 & Poecile atricapillus GI trac-associated virus & NC_027776 & DNA, circular \\
\hline 17 & Rat stool-associated circular ssDNA virus & NC_027777 & DNA, circular \\
\hline 18 & Scaledrop disease virus & NC_027778 & DNA, linear. \\
\hline 19 & Human papillomavirus & NC_001693 & DNA, linear. \\
\hline 20 & Petrochirus diogenes giant hermit crab virus & NC_027780 & DNA, circular \\
\hline 21 & Aiptasia sp. sea anemone associated virus & NC_027781 & DNA, circular \\
\hline 22 & Didemnum sp. Sea Squirt associated virus & NC_027782 & DNA, circular \\
\hline 23 & Littorina sp. Associated circular virus & NC_027783 & DNA, circular \\
\hline 24 & Callinectes ornatus blue crab virus & NC_027784 & DNA, circular \\
\hline 25 & Callinectes sapidus virus & NC_027785 & DNA, circular \\
\hline 26 & Palaemonetes intermedius brackish virus & NC_027786 & DNA, circular \\
\hline 27 & Gooseberry vein banding virus & NC_018105 & DNA, circular \\
\hline 28 & Gyrovirus & NC_017091 & DNA, circular \\
\hline 29 & Tianjin totivirus & NC_017084 & dDNA, linear. \\
\hline 30 & Canary polyomavirus & NC_017085 & DNA, linear. \\
\hline 31 & Leucania separata nuclear polyhedrsis virus & NC_008348 & DNA, circular. \\
\hline 32 & Ageratum leaf curl Cameroon virus & NC_014645 & DNA, circular \\
\hline 33 & Human papyloma virus type 50 virus & NC_001691 & DNA, linear. \\
\hline
\end{tabular}




\section{Continued}

\begin{tabular}{|c|c|c|c|}
\hline 34 & Human papylomavirus type 60 virus & NC_001693 & DNA, linear. \\
\hline 35 & Human papylomavirus type 48 virus & NC_001691 & DNA, linear. \\
\hline 36 & Citrus chlorotic dwarf associated virus & NC_018151 & DNA, circular \\
\hline 37 & Sibine fusca densovirus & NC_018399 & DNA, linear. \\
\hline 38 & Papillo polyxenes densovirus & NC_018450 & DNA, linear. \\
\hline 39 & French bean severe leaf curl virus & NC_018453 & DNA, circular \\
\hline 40 & Centrosema yellow spot virus & NC_016998 & DNA, circular \\
\hline 41 & Cassava mosaic Madagascar A virus & NC_017004 & DNA, circular \\
\hline 42 & Cassava mosaic Madagascar B virus & NC_017005 & DNA, circular \\
\hline 43 & Sulfolobus virus & NC_001338 & DNA, circular \\
\hline 44 & Minute virus of mice & NC_001510 & DNA, linear. \\
\hline 45 & Bovine parvovirus & NC_001540 & DNA, linear. \\
\hline 46 & Mastomys natalensis papillomavirus & NC_001605 & DNA, circular \\
\hline 47 & Simian 40 virus & NC_001669 & DNA, circular \\
\hline 48 & Rheusus monkey papillomavirus & NC_001678 & DNA, circular \\
\hline 49 & Adeno-associated virus & NC_001829 & DNA, circular \\
\hline 50 & Diatraeasaccharalisdensovirus & NC_001899 & DNA, circular \\
\hline 51 & Melanoplus sanguinipes entomopoxvirus & NC_001993 & DNA, linear. \\
\hline 52 & Rabbit oral papilloma virus & NC_002232 & DNA, linear. \\
\hline 53 & Murine pneumotropic virus & NC_001505 & DNA, circular \\
\hline 54 & Goose pavovirus & NC_001701 & DNA, linear. \\
\hline 55 & Porcine endogenous retrovirus $\mathrm{E}$ & NC_003059 & DNA, linear. \\
\hline 56 & Dhalia mosaic virus & NC_018616 & DNA, circular \\
\hline 57 & African pouched rat virus & NC_026439 & RNA, circular \\
\hline 58 & Equine adenovirus & NC_027705 & RNA, linear. \\
\hline 59 & Arracacha mottle virus & NC_018176 & RNA, linear \\
\hline 60 & Phopivirus & NC_027818 & RNA, linear. \\
\hline 61 & Dengue virus 2 & NC_01474 & RNA, linear. \\
\hline 62 & Parramatta river virus & NC_027817 & RNA, linear. \\
\hline 63 & West Nile virus & NC_009942 & RNA,linear.. \\
\hline 64 & DeBrazza's monkey virus & NC_026509 & RNA, linear. \\
\hline 65 & Fizroy River virus & NC_027700 & RNA, linear. \\
\hline 66 & Trichomonas vaginalis virus & NC_027701 & RNA, linear. \\
\hline 67 & Luffa aphid-borne yellows virus & NC_027703 & RNA, linear. \\
\hline
\end{tabular}




\section{Continued}

\begin{tabular}{|c|c|c|c|}
\hline 68 & Lettuce italian necrotic virus & NC_027706 & RNA, linear. \\
\hline 69 & Spanish goat encephalitis virus & NC_027709 & RNA, linear. \\
\hline 70 & Dromedary astrovirus & NC_027711 & RNA, linear. \\
\hline 71 & Tobaco virus & NC_027712 & RNA, linear. \\
\hline 72 & Beauveria bassiana RNA virus & NC_027428 & RNA, linear. \\
\hline 73 & Fe-de-lance virus & NC_005084 & RNA, linear. \\
\hline 74 & Persimmon crytic virus & NC_017988 & RNA, linear. \\
\hline 75 & Rhizoctonia solani RNA virus & NC_027529 & RNA, linear. \\
\hline 76 & Japanese holly fern mottle virus & NC_013134 & RNA, linear. \\
\hline 77 & Chaoyang virus & NC_017086 & RNA, linear. \\
\hline 78 & Rabit coronavirus & NC_017083 & RNA, linear. \\
\hline 79 & SFTS virus seg, L & NC_018136 & RNA, linear. \\
\hline 80 & SFTS virus seg, S & NC_018137 & RNA, linear. \\
\hline 81 & SFTS virus, seg, $M$ & NC_018138 & RNA, linear. \\
\hline 82 & Chrysantheum B virus & NC_009087 & RNA, linear. \\
\hline 83 & Marine birna virus & NC_008019 & RNA, linear. \\
\hline 84 & Viral hemorrhagic septicemia virus & NC_000855 & RNA, linear. \\
\hline 85 & Saccharomyces cerrevisiae virus & NC_001641 & RNA, linear. \\
\hline 86 & Bat hepevirus & NC_018382 & RNA, linear. \\
\hline 87 & Grapevine Anatolian ringspot RNA 1virus & NC_018383 & RNA, linear. \\
\hline 88 & Sweet potato virus C-6 & NC_018448 & RNA, linear. \\
\hline 89 & Grapevine virus $\mathrm{F}$ & NC_018458 & RNA,.linear. \\
\hline 90 & Porcine coronavirus HKU 15 & NC_016990 & RNA, linear. \\
\hline 91 & White-eye coronavirus & NC_016991 & RNA, linear. \\
\hline 92 & Magpie-robin coronvirus & NC_016993 & RNA, linear. \\
\hline 93 & Night-heron coronavirus & NC_016994 & RNA, linear. \\
\hline 94 & Wigeon coronavirus & NC_016995 & RNA, linear. \\
\hline 95 & Common-moorhen coronavirus & NC_016996 & RNA, linear. \\
\hline 96 & Donggang virus & NC_016997 & RNA, linear. \\
\hline 97 & Clitocybe odora virus & NC_017003 & RNA, linear. \\
\hline 98 & Mercadeo virus & NC_027819 & RNA, linear. \\
\hline 99 & Opium poppy mosaic virus & NC_027710 & RNA, linear. \\
\hline 100 & Groundnut rossete virus & NC_003603 & RNA, linear. \\
\hline
\end{tabular}

